\title{
Monetary/Fiscal Policy Mix and Agents' Beliefs
}

\author{
Francesco Cosmin llut \\ Bianchi \\ Duke University \\ Duke University
}

May 2014

ERID Working Paper Number 119

This paper can be downloaded without charge from the Social Science Research Network Electronic Paper Collection:

http://ssrn.com/abstract $=1990475$

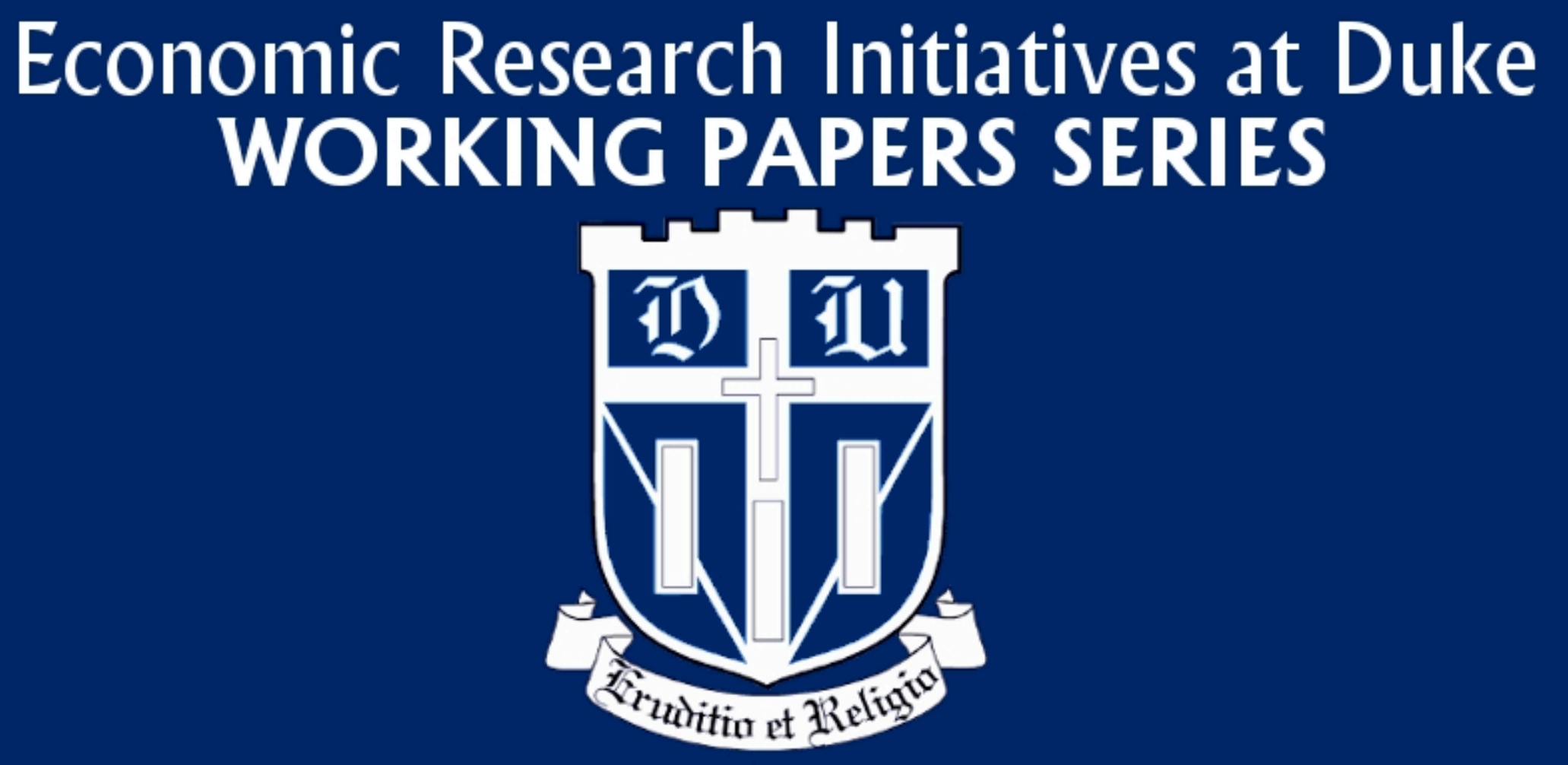




\title{
Monetary/Fiscal Policy Mix and Agents' Beliefs*
}

\author{
Francesco Bianchi Cosmin Ilut \\ Duke University Duke University \\ CEPR and NBER NBER
}

May 2014

\begin{abstract}
We reinterpret post World War II US economic history using an estimated microfounded model that allows for changes in the monetary/fiscal policy mix. We find that the fiscal authority was the leading authority in the '60s and the '70s. The appointment of Volcker marked a change in the conduct of monetary policy, but inflation dropped only when fiscal policy accommodated this change two years later. In fact, a disinflationary attempt of the monetary authority leads to more inflation if not supported by the fiscal authority. If the monetary authority had always been the leading authority or if agents had been confident about the switch, the Great Inflation would not have occurred and debt would have been higher. This is because the rise in trend inflation and the decline in debt of the '70s were caused by a series of fiscal shocks that are inflationary only when monetary policy accommodates fiscal policy. The reversal in the debtto-GDP ratio dynamics, the sudden drop in inflation, and the fall in output of the early '80s are explained by the switch in the policy mix itself. If such a switch had not occurred, inflation would have been high for another fifteen years. Regime changes account for the stickiness of inflation expectations during the '60s and the '70s and for the break in the persistence and volatility of inflation.
\end{abstract}

JEL Codes: E31, E58, C11

Keywords: Fiscal policy, monetary policy, inflation, Markov-switching DSGE, Bayesian methods.

${ }^{*}$ We are grateful to Toni Braun, Craig Burnside, John Cochrane, Jesus Fernandez-Villaverde, Tim Fuerst, Yuriy Gorodnichenko, Nikolay Iskrev, Nir Jaimovich, Alejandro Justiniano, Eric Leeper, Karel Mertens, Giorgio Primiceri, Barbara Rossi, Juan Rubio-Ramirez, Martin Schneider, Chris Sims, Harald Uhlig, Tao Zha, and all seminar participants at the meeting of the NBER Monetary Economics group, Minneapolis Fed, Atlanta Fed, Bank of Canada, Cleveland Fed, Board of Governors of the FRS, Duke University, and the "Old and New Ideas about Fiscal Policy" conference at UCSB for useful comments and discussions. We thank Fernando Martin for sharing his data on the number of meetings between the US Presidents and the Fed Chairmen. Correspondence: Francesco Bianchi, francesco.bianchi@duke.edu. 


\section{Introduction}

Central bankers seem particularly aware of the potential risks linked to the lack of fiscal discipline. The current Fed Chairman himself claimed that [t]he primary cause of the Great Inflation, most economists would agree, was over-expansionary monetary and fiscal policies, beginning in the mid1960 s and continuing, in fits and starts, well into the 1970s. The fiscal expansion of this period had a variety of elements, including heavy expenditures for the Vietnam War and President Johnson's Great Society initiatives. Monetary policy first accommodated the fiscal expansion, and then [...] began to power the inflationary surge on its own. (Bernanke, 2003). Nevertheless, when studying the evolution of inflation and output over the past sixty years, the role of fiscal policy has often been neglected. This is despite the fact that in many of the general equilibrium models that are routinely used to analyze the effects of monetary policy, the central bank is able to control inflation only under the assumption that the fiscal authority is committed to adjusting primary surpluses in order to stabilize debt. As effectively shown by Leeper (1991), when this commitment is absent model dynamics in a rational expectations general equilibrium model depend on the parameters characterizing the joint behavior of the monetary and fiscal authorities and policy interventions can have perverse and surprising effects. This has induced economists such as Cochrane (1998, 2001) and Sims (2011) to conjecture that the original sin that led to the rise of inflation in the '70s should be sought out in the conduct of fiscal policy during those years.

Figure 1 contextualizes the events highlighted by Bernanke, reporting the evolution of inflation, ex-post real interest rate, and debt-to-GDP ratio over the period 1955-2009 together with the first reference to the Great Society initiatives ever made by President Johnson (May 1964) and the appointment of Paul Volcker to Fed Chairman (August 1979). Some stylized facts can be identified. First, trend inflation increased steadily over the first half of the sample, while over the same period the debt-to-GDP ratio declined smoothly. During this time inflation was very persistent and volatile and real interest rates were low. Then, in the early '80s, a few quarters after the appointment of Volcker, inflation experienced a sudden and sharp drop that coincided with a deep recession and a jump in real interest rates. At the same time, the debt-to-GDP ratio started increasing steadily, until the early '90s. Since then, inflation has been stable and its movements have been mostly at high frequencies.

We reinterpret the events described above in light of an estimated micro-founded Dynamic Stochastic General Equilibrium (DSGE) model in which the monetary/fiscal policy mix and the volatility of the structural shocks are subject to regime changes. As in Sims and Zha (2006), movements across regimes are potentially recurrent and controlled by two independent Markov-switching (MS) processes. However, in our general equilibrium model agents are aware of the possibility of regime changes and they form expectations taking them into account. We then solve the model using the methods developed by Farmer, Waggoner, and Zha (2009, 2011). Specifically, we allow for a total of three policy regimes and two volatility regimes. In order to capture the idea that the balance of power between the monetary and fiscal authorities might have changed over time, we allow for two 


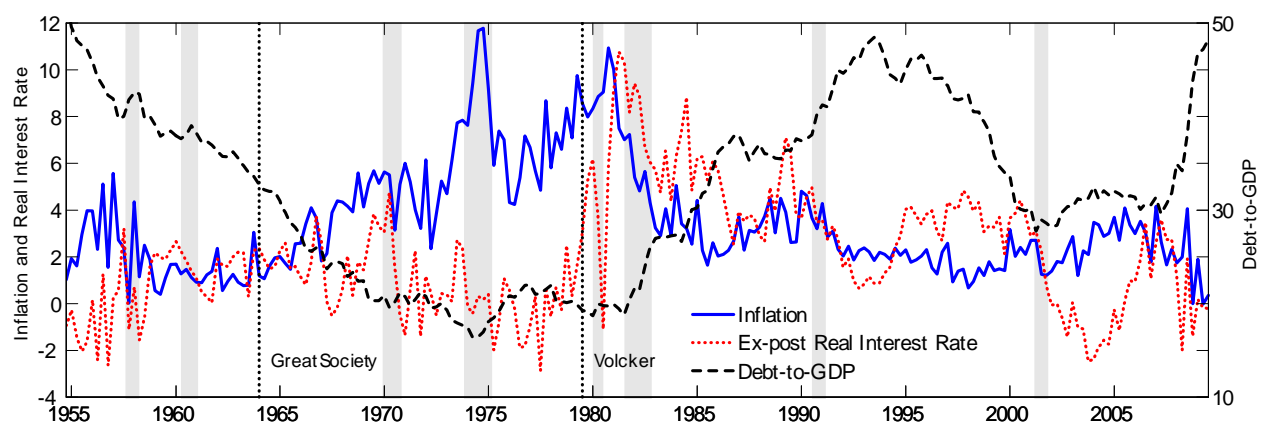

Figure 1: Annualized quarterly inflation, Real Interest Rate, and debt-to-GDP ratio over the sample 1954:Q3-2009:Q4. The grey shaded areas represent the NBER recessions, while the two red vertical lines mark President Johnson's first ever public reference to the Great Society (May 1964) and the appointment of Paul Volcker (August 1979). Inflation is measured taking the log-difference of the GDP deflator, the ex-post real interest rate is computed taking the difference between the FFR and realized inflation in the following period, while the debt-to-GDP ratio is obtained taking the ratio between the stock of debt held by the public and annualized GDP.

polar policy regimes. In the first polar case, the monetary authority is the leading authority: The Taylor principle is satisfied and the fiscal authority is committed to keeping debt on a stable path. In the second polar case, the fiscal authority is the leading authority and does not necessarily respond to movements in the debt-to-GDP ratio, while the central bank's actions do not satisfy the Taylor principle. The third policy regime captures the possibility of a conflict between the two authorities: The central bank reacts strongly to inflation, while the fiscal authority does not move taxes in response to debt. In the language of Leeper (1991) these three regimes correspond to Active Monetary/Passive Fiscal (AM/PF), Passive Monetary/Active Fiscal (PM/AF), and Active Monetary/Active Fiscal $(\mathrm{AM} / \mathrm{AF})$, respectively.

We find that the fiscal authority was the leading authority from the late '50s until the appointment of Volcker. This event coincided with a change in the conduct of monetary policy at the end of 1979, but the fiscal authority accommodated such a change only at the end of 1981, after Reagan was elected. The monetary authority has been the leading authority since then. In the late '60s and mid70s monetary policy became active for short periods of time, but without a corresponding change in the behavior of the fiscal authority. Finally, our estimated transition matrix implies that the PM/AF regime is the most recurrent regime and that when a conflict between the two authorities arises the fiscal authority prevails most of the time.

We use actual and counterfactual impulse responses to understand the role of agents' beliefs and how fiscal disturbances propagate through the economy across different regimes. Under the PM/AF the fiscal authority is not committed to increasing taxation to keep the debt-to-GDP ratio balanced. Therefore, a shock to government expenditure determines a long lasting increase in inflation. Given that the Taylor principle does not hold, the central bank accommodates the increase in inflation, the real interest rate falls, and growth accelerates. At the same time, agents revise expectations about future short term interest rates upward causing a decline in the price of long term bonds. The increase in growth, the drop in the price of long term bonds, and the low real interest rates determine a decline in the debt-to-GDP ratio. 
Under the AM/PF regime, instead, agents expect that the necessary fiscal adjustments will be made and the impact of the expenditure shock on inflation is largely reduced. However, given that agents form expectations taking into account the possibility of regime changes, the increase in the fiscal burden still determines some inflationary pressure. The central bank tries to counteract the increase in inflation, determining a small but persistent decline in real activity. These inflationary effects would disappear if the $\mathrm{AM} / \mathrm{PF}$ regime were perceived as Fully credible, i.e. if agents expected to remain under the $\mathrm{AM} / \mathrm{PF}$ forever.

Agents' beliefs also play a key role when a conflict between the two authorities arises, as in the $\mathrm{AM} / \mathrm{AF}$ regime. In this case, agents understand that the fiscal authority is more likely to prevail and that the additional fiscal burden will be inflated away. Therefore, a positive fiscal imbalance determines an increase in inflation. However, now the central bank does not accommodate the increase in inflation, pushing the economy into a recession. This results in a further increase in the amount of debt that agents expect will be inflated away, determining additional inflationary pressure. Therefore, if inflation is high as a result of a positive fiscal imbalance, the central bank is not able to bring inflation down without coordinating with the fiscal authority. Finally, across all regimes the inflationary effects of fiscal imbalances would disappear if the central bank were perceived to be more likely to prevail in case of a conflict between the two authorities. This would make agents confident about the possibility of moving to the $\mathrm{AM} / \mathrm{PF}$ regime, regardless of the regime that they are currently in.

These model dynamics and the sequence of events that we uncover provide a unified theory for the stylized facts described above. Using counterfactual simulations in which the non-policy shocks hitting the economy are left unchanged, we show that if the $\mathrm{AM} / \mathrm{PF}$ regime had been in place for the entire sample or if agents had been confident about the possibility of entering such a regime, the Great Inflation would not have occurred and the debt-to-GDP ratio would have been higher. This is because in our model the rise in trend inflation and the low debt of the '70s are two sides of the same coin and are caused by a series of expenditure shocks that are largely inflationary only when the $\mathrm{PM} / \mathrm{AF}$ regime is in place. Consequently, the moment policymakers' behavior changes or agents are confident that it will change in the near future, the inflationary shocks of the '60s and 70s are neutralized, trend inflation does not rise, and the debt-to-GDP ratio and real interest rates turn out to be higher.

In the same way the PM/AF regime plays a key role in explaining the Great Inflation and the contemporaneous decline in the debt-to-GDP ratio, the change in the policy mix at the end of 1981 is the driving force behind the reversal of these dynamics and the large recession that occurred during those years. To make this point, we construct a different set of counterfactual simulations in which we restrict all the shocks that occurred after the end of 1979 to zero and then consider different scenarios about the evolution of policymakers' behavior. We argue that the change in monetary policy at the end of 1979 did not cause a drop in inflation because it lacked the support of the fiscal authority. In this respect, this disinflationary attempt was similar to previous ones that occurred 
in the '60s and in the '70s. It is only in the moment that the fiscal authority accommodated the change in monetary policy at the end of 1981 that inflation started falling. The resulting revision in expectations about the way debt will be stabilized rationalizes the stylized facts described above, with inflation experiencing a quick drop, the economy entering a recession, real interest rates rising sharply, and debt increasing. If instead the switch to the AM/PF regime had not occurred, inflation would have been higher for another fifteen years and the reversal in the debt-to-GDP dynamics would not have occurred. Finally, the disinflation would have been faster and less painful if agents had perceived the change in the policy mix as fully credible given that this would have made the fiscal imbalances inherited from the past not inflationary. Therefore, in our model, regime changes, not a sequence of shocks, explain the events of the early ' 80 s.

We then compute the model implied evolution of inflation expectations and we compare them with the actual data. The model is able to replicate the smooth increase that started in the mid-' 60 s, the absence of a significant response to the appointment of Volcker and to the disinflationary attempts of the late '60s and mid-'70s, and the decline that started in the early '80s. This is because the change in the balance of power between the monetary and fiscal authorities plays a key role in explaining the break in the volatility and persistence of inflation that occurred in the early '80s (Stock and Watson, 2007, Cogley, Primiceri, and Sargent, 2010). When the monetary authority accommodates the behavior of the fiscal authority, inflation is substantially more volatile and persistent, as was in fact the case over the first half of the sample, and fiscal imbalances are very important. Once the economy moves to the $\mathrm{AM} / \mathrm{PF}$ regime the contribution of these shocks to inflation volatility is substantially reduced and inflation becomes less volatile and persistent. The fact that policy changes have pervasive effects on the persistence and volatility of inflation provides an important source of identification. In fact, at longer horizons policy uncertainty turns out to be even more important than breaks in the volatility of the exogenous shocks.

Our empirical findings are consistent with historical accounts and anecdotes about the evolution of the monetary/fiscal policy interaction. For example, Meltzer (2009) argues that Martin and Burns were heavily influenced by the fiscal authority in their decisions, while Volcker received full and public support by the Reagan administration to put an end to the high inflation. Furthermore, we show that the long term component of government expenditure experienced an acceleration after 1964, when President Johnson made the first ever public reference to the Great Society, providing evidence for the argument proposed by Bernanke that the first spur of inflation was triggered by fiscal policy.

The study of the interaction between fiscal and monetary policies in determining inflation dynamics goes back to the seminal contribution of Sargent and Wallace (1981), who consider the problem in a deterministic environment, and proceeds with Leeper (1991), Sims (1994), and Woodford (1994, 1995, 2001) who focus on the problem of price determinacy. ${ }^{1}$ Cochrane $(1998,2001)$ takes a modelfree frictionless view of US inflation, in which a non-Ricardian regime is always in place and the real

\footnotetext{
${ }^{1}$ See Cochrane (2011) for an effective discussion of the difference between the early approach of Sargent and Wallace (1981) and the subsequent analysis based on the Fiscal Theory of Price Level. See Atkeson, Chari, and Kehoe (2009) for an alternative approach to price determination in monetary general equilibrium models.
} 
interest is exogenously determined. Therefore, movements in inflation are explained by revisions in future expected real surpluses and the debt policy implemented by the fiscal authority. Our theoretical framework is more similar to Leeper (1991), given that we allow for changes in policy rules in a fully specified DSGE model, but we follow Cochrane $(1998,2001)$ in recognizing the importance of modeling a maturity structure of government debt.

Orphanides (2002), Primiceri (2006), and Sargent, Williams, and Zha (2006) explain the rise of inflation as the result of the evolution of central bank's beliefs about the state or structure of the economy. With respect to these studies, two important insights emerge from our work. First, if inflation is high because of a lack of fiscal discipline, disinflationary attempts by the monetary authority lead to more inflation if not supported by the fiscal authority. Second, changes in the balance of power between the monetary and fiscal authorities determine breaks in the persistence and volatility of inflation. Therefore, some key features that in those papers have been attributed to unforeseen structural breaks, such as a high sacrifice ratio, a positive output gap, and high inflation persistence, are in the context of our paper explained by changes in the monetary/fiscal policy mix. This implies that such features disappear the moment fiscal discipline is restored.

In our counterfactual simulations changes in policymakers' behavior have a significant impact on the dynamics of inflation. This is in sharp contrast with previous studies that conduct counterfactual simulations focusing exclusively on monetary policy. In these studies replacing Burns with Volcker would have implied only a minor reduction of inflation in the '70s and removing the appointment of Volcker in August '79 would have only slightly delayed the return of inflation to the steady state. This is because different monetary policy regimes only affect how the burden of adverse shocks is redistributed between output and inflation. Instead, when the entire policy mix is modified a series of fiscal shocks that are inflationary under the $\mathrm{PM} / \mathrm{AF}$ regime are completely neutralized when the monetary authority is the leading authority.

In our model, the government expenditure shocks affect not only the fiscal variables, but they also contribute to the large and upward trending inflation of the 1970s. Therefore, our explanation for the Great Inflation implies additional data restrictions on the inflationary shocks from the set of observables. In the previous literature the Great Inflation is mostly caused by latent shocks, whose only empirical discipline is dictated by the standard model cross-equation implications on the observed data. In contrast, in our model the inflationary fiscal shocks are further identified by the fact that the fiscal block of the economy is included as part of the observables. In particular, we show that these shocks resemble the low-frequency component of the observed government expenditure.

As Davig and Leeper (2006), we find that fiscal imbalances determine inflationary pressure even under the AM/PF regime. These authors estimate Markov-switching Taylor and fiscal rules, plugging them into a calibrated DSGE model. Instead, in this paper we estimate the policy rules and the other parameters of the model jointly. In this respect, the paper is related to the growing literature that allows for parameter instability in DSGE models. Justiniano and Primiceri (2008) allow for heteroskedasticity, while Schorfheide (2005), Liu, Waggoner, and Zha (2011), Bianchi (2013b), Davig 
and Doh (2013), Fernandez-Villaverde, Guerron-Quintana, and Rubio-Ramirez (2010), and Baele, Bekaert, Cho, Inghelbrecht, and Moreno (2011) also model changes in the parameters of the Taylor rule or the inflation target. Coibion and Gorodichenko (2011) study the consequences of the high trend inflation of the '70s for price determinacy. In our model we find very persistent movements in inflation that resemble changes in trend inflation as a result of fiscal shocks.

The content of this paper can be summarized as follows. Section 2 describes the model. Section 3 presents the estimates. Section 4 conducts the counterfactual simulations. Section 5 shows that the model can account for changes in inflation persistence and volatility and for the break in the dynamics of inflation expectations. Section 6 puts our results into a historical perspective. Section 7 concludes.

\section{The Model}

We make use of a new-Keynesian model similar to the one employed by Clarida, Gali, and Gertler (2000) and Lubik and Schorfheide (2004), augmented with a fiscal block, external habits, and a maturity structure for government debt. Furthermore, we allow for changes in policymakers' behavior and stochastic volatility. These changes are modeled as two independent MS processes. We introduce two state variables $\xi_{t}^{s p}$ and $\xi_{t}^{v o}$, capturing the monetary policy regime and the volatility regime that are in place at time $t$. Here and in what follows, $s p$ and vo stand, respectively, for structural parameters and volatilities. The state variables take on a finite number of values $j_{s p}=1, \ldots, m_{s p}$ and $j_{v o}=1, \ldots, m_{v o}$ and evolve according to the transition matrices $H^{s p}$ and $H^{v o}$, respectively. More details about the number and the nature of the regimes will be provided below.

\subsection{Model description}

Households. The representative household maximizes the following utility function:

$$
E_{0}\left[\sum_{s=0}^{\infty} \beta^{s} e^{d_{s}}\left[\log \left(C_{s}-\Phi C_{s-1}^{A}\right)-h_{s}\right]\right]
$$

subject to the budget constraint:

$$
P_{t} C_{t}+P_{t}^{m} B_{t}^{m}+P_{t}^{s} B_{t}^{s}=P_{t} W_{t} h_{t}+B_{t-1}^{s}+\left(1+\rho P_{t}^{m}\right) B_{t-1}^{m}+P_{t} D_{t}-T_{t}+T R_{t}
$$

where $D_{t}$ stands for real dividends paid by the firms, $C_{t}$ is consumption, $P_{t}$ is the aggregate price level, $h_{t}$ is hours, $W_{t}$ is the real wage, $T_{t}$ stands for lump-sum taxes, $T R_{t}$ denotes transfers, and $C_{t}^{A}$ represents the average level of consumption in the economy. The parameter $\Phi$ captures the degree of external habit. The preference shock $d_{s}$ has mean zero and time series representation: $d_{t}=\rho_{d} d_{t-1}+\sigma_{d, \xi_{t}^{v o}} \varepsilon_{d, t}$. Following Eusepi and Preston (2012) and Woodford (2001), we assume that there are two types of government bonds: One-period government bonds, $B_{t}^{s}$, in zero net supply 
with price $P_{t}^{s}$ and a more general portfolio of government bonds, $B_{t}^{m}$, in non-zero net supply with price $P_{t}^{m}$. The former debt instrument satisfies $P_{t}^{s}=R_{t}^{-1}$. The latter debt instrument has payment structure $\rho^{T-(t+1)}$ for $T>t$ and $0<\rho<1$. The value of such an instrument issued in period $t$ in any future period $t+j$ is $P_{t+j}^{m-j}=\rho^{j} P_{t+j}^{m}$. The asset can be interpreted as a portfolio of infinitely many bonds, with weights along the maturity structure given by $\rho^{T-(t+1)}$. Varying the parameter $\rho$ varies the average maturity of debt.

Firms. The representative monopolistically competitive firm $j$ faces a downward-sloping demand curve:

$$
Y_{t}(j)=\left(P_{t}(j) / P_{t}\right)^{-1 / v_{t}} Y_{t}
$$

where the parameter $1 / v_{t}$ is the elasticity of substitution between two differentiated goods. Firms take as given the general price level, $P_{t}$, and the level of real activity, $Y_{t}$. Whenever a firm changes its price, it faces quadratic adjustment costs represented by an output loss:

$$
A C_{t}(j)=.5 \varphi\left(P_{t}(j) / P_{t-1}(j)-\Pi_{t-1}^{\varsigma} \Pi^{1-\varsigma}\right)^{2} Y_{t}(j) P_{t}(j) / P_{t}
$$

where $\Pi_{t}=P_{t} / P_{t-1}$ is gross inflation at time $t, \Pi$ is the corresponding steady state, and the parameter $\varsigma$ controls the level of indexation to lagged inflation. Shocks to the elasticity of substitution imply shocks to the markup $\aleph_{t}=1 /\left(1-v_{t}\right)$. We assume that the rescaled markup $\mu_{t}=\frac{\kappa}{1+\varsigma \beta} \log \left(\aleph_{t} / \aleph\right)$ follows an autoregressive process, $\mu_{t}=\rho_{\mu} \mu_{t-1}+\sigma_{\mu, \xi_{t}^{v o}} \epsilon_{\mu, t}$, where $\kappa \equiv \frac{1-v}{v \varphi \Pi^{2}}$ is the slope of the Phillips curve. The firm chooses the price $P_{t}(j)$ to maximize the present value of future profits:

$$
E_{t}\left[\sum_{s=t}^{\infty} Q_{s}\left(\left[P_{s}(j) / P_{s}\right] Y_{s}(j)-W_{s} h_{s}(j)-A C_{s}(j)\right)\right]
$$

where $Q_{s}$ is the marginal value of a unit of consumption good. Labor is the only input in the firm production function, $Y_{t}(j)=A_{t}^{1-\alpha} h_{t}(j)$, where total factor productivity $A_{t}$ evolves according to an exogenous process: $\ln \left(A_{t} / A_{t-1}\right)=\gamma+a_{t}, a_{t}=\rho_{a} a_{t-1}+\sigma_{a, \xi_{t}^{v o}} \varepsilon_{a, t}, \epsilon_{a, t} \sim N(0,1)$.

Government. Imposing the restriction that one-period debt is in zero net supply, the flow budget constraint of the federal government is given by:

$$
P_{t}^{m} B_{t}^{m}=B_{t-1}^{m}\left(1+\rho P_{t}^{m}\right)-T_{t}+E_{t}+T P_{t}
$$

where $P_{t}^{m} B_{t}^{m}$ is the market value of debt and $T_{t}$ and $E_{t}$ represent federal tax revenues and federal expenditures, respectively. Government expenditure is the sum of federal transfers and goods purchases: $E_{t}=P_{t} G_{t}+T R_{t}$. The term $T P_{t}$ is a shock that is meant to capture a series of features that are not explicitly modeled here, such as changes in the maturity structure and the term premium. This shock is necessary to avoid stochastic singularity when estimating the model given that we treat debt, taxes, and expenditures as observables. ${ }^{2}$ We rewrite the federal government budget constraint

\footnotetext{
${ }^{2}$ Alternative approaches consist of excluding one of the fiscal components or including an observation error. Our results are robust to these alternative specifications.
} 
in terms of debt-to-GDP ratio $b_{t}^{m}=\left(P_{t}^{m} B_{t}^{m}\right) /\left(P_{t} Y_{t}\right)$ :

$$
b_{t}^{m}=\left(b_{t-1}^{m} R_{t-1, t}^{m}\right) /\left(\Pi_{t} Y_{t} / Y_{t-1}\right)-\tau_{t}+e_{t}+t p_{t}
$$

where all the variables are now expressed as a fraction of GDP, $R_{t-1, t}^{m}=\left(1+\rho P_{t}^{m}\right) / P_{t-1}^{m}$ is the

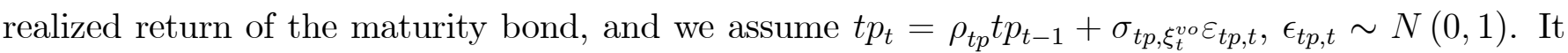
is worth pointing out that in equilibrium revisions of future expected short term interest rates will imply fluctuations in the price of maturity bonds and, consequently, in $R_{t-1, t}^{m}$ and $b_{t}^{m}$.

The linearized federal government expenditure as a fraction of GDP, $\widetilde{e}_{t}$, is the sum of a short term component $\widetilde{e}_{t}^{S}$ and a long term component $\widetilde{e}_{t}^{L}\left(\widetilde{e}_{t}=\widetilde{e}_{t}^{L}+\widetilde{e}_{t}^{S}\right):^{3}$

$$
\begin{aligned}
& \widetilde{e}_{t}^{L}=\rho_{e^{L}} \widetilde{e}_{t-1}^{L}+\sigma_{e^{L}, \xi_{t}^{v o}} \epsilon_{e^{L}, t}, \epsilon_{e^{L}, t} \sim N(0,1) \\
& \widetilde{e}_{t}^{S}=\rho_{e^{S}} \widetilde{e}_{t-1}^{S}+\left(1-\rho_{e^{S}}\right) \phi_{y}\left(\widehat{y}_{t}-\widehat{y}_{t}^{*}\right)+\sigma_{e^{S}, \xi_{t}^{v o}} \epsilon_{e^{S}, t}, \epsilon_{e^{S}, t} \sim N(0,1) .
\end{aligned}
$$

The long term component is assumed to be completely exogenous and it is meant to capture the large programs that arise as the result of a political process that is not modeled here. Instead, the short term component accounts for the response of government expenditure to the business cycle and responds to the (log-linearized) output gap, $\widehat{y}_{t}-\widehat{y}_{t}^{*}$. The total federal government expenditure is then divided into transfers, $T R_{t}$, and government purchases, $G_{t}$. Market clearing requires $Y_{t}=G_{t}+C_{t}$. We then define the variable $\chi_{t} \equiv P_{t} G_{t} / E_{t}$ to be the fraction of federal expenditure devoted to government purchases and we assume that:

$$
\widetilde{\chi}_{t}=\rho_{\chi} \widetilde{\chi}_{t-1}+\left(1-\rho_{\chi}\right) \iota_{y}\left(\widehat{y}_{t}-\widehat{y}_{t}^{*}\right)+\sigma_{\chi, \xi_{t}^{v o}} \epsilon_{\chi, t}, \epsilon_{\chi, t} \sim N(0,1)
$$

Monetary and Fiscal Rules. The central bank moves the Federal Funds rate (FFR) according to the rule:

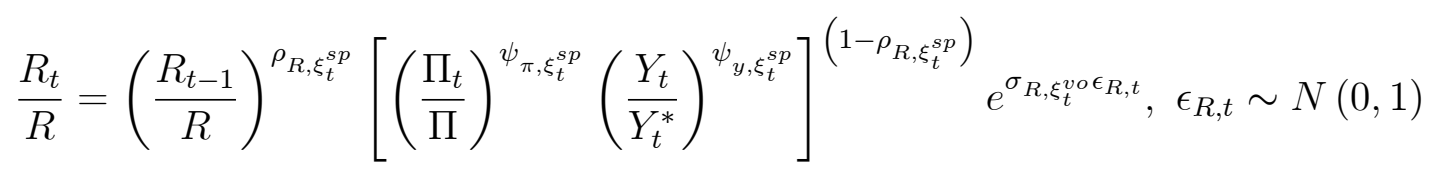

where $R$ is the steady-state gross nominal interest rate. The federal fiscal authority moves taxes according to the rule:

$$
\widetilde{\tau}_{t}=\rho_{\tau, \xi_{t}^{s p}} \widetilde{\tau}_{t-1}+\left(1-\rho_{\tau, \xi_{t}^{s p}}\right)\left[\delta_{b, \xi_{t}^{s p}} \widetilde{b}_{t-1}^{m}+\delta_{e} \widetilde{e}_{t}+\delta_{y}\left(\widehat{y}_{t}-\widehat{y}_{t}^{*}\right)\right]+\sigma_{\tau, \xi_{t}^{v o}} \epsilon_{\tau, t}, \epsilon_{\tau, t} \sim N(0,1)
$$

where $\widetilde{\tau}_{t}$ represents linear deviations of the tax-to-GDP ratio $\tau_{t} \equiv T_{t} /\left(P_{t} Y_{t}\right)$ from its own steady state. Note that taxes respond to the total level of expenditure, $\delta_{e}$, and real activity, $\delta_{y}$. The

\footnotetext{
${ }^{3}$ In what follows, $\widehat{x}_{t} \equiv \log \left(\left(X_{t} / A_{t}\right) /(X / A)\right)$ represents the percentage deviation of a detrended variable from its own steady state. For all the variables normalized with respect to GDP (debt, expenditure, and taxes) $\widetilde{x}_{t}$ denotes a linear deviation $\left(\widetilde{x}_{t}=X_{t}-X\right)$, while for all the other variables $\widetilde{x}_{t}$ denotes a percentage deviation $\left(\widetilde{x}_{t}=\log \left(X_{t} / X\right)\right)$. This distinction avoids having the percentage change of a percentage.
} 


\begin{tabular}{c||cc} 
& Active Fiscal (AF) & Passive Fiscal (PF) \\
\hline \hline Active Monetary (AM) & No Solution & Determinacy \\
Passive Monetary (PM) & Determinacy & Indeterminacy
\end{tabular}

Table 1: Partition of the parameter space according to existence and uniqueness of a solution (Leeper (1991)).

importance of the response to debt $\left(\delta_{b, \xi_{t}^{s p}} \geq 0\right)$ will be discussed below.

\subsection{Monetary/Fiscal Policy Mix}

Before describing the regime changes that we allow for, we illustrate the consequences of explicitly modeling the behavior of the fiscal authority. In order to do so, we shall simplify the two linearized policy rules as follows:

$$
\widetilde{R}_{t}=\psi_{\pi, \xi_{t}^{s p}} \widetilde{\pi}_{t} \text { and } \widetilde{\tau}_{t}=\delta_{b, \xi_{t}^{s p}} \widetilde{b}_{t-1}^{m}
$$

If we then substitute the tax rule in the linearized law of motion for the debt-to-GDP ratio and isolate the resulting coefficient for lagged debt, we get:

$$
\widetilde{b}_{t}^{m}=\left(\beta^{-1}-\delta_{b, \xi_{t}^{s p}}\right) \widetilde{b}_{t-1}^{m}+\ldots
$$

Leeper (1991) shows that, in absence of regime changes, we can distinguish four regions of the parameter space according to existence and uniqueness of a solution to the model. These regions are summarized in Table 1 and in general they are a function of all parameters of the model. However, in practice, the two linearized policy rules are key in determining existence and uniqueness of a solution. There are two determinacy regions. The first one, Active Monetary/Passive Fiscal (AM/PF), is the most familiar one: The Taylor principle is satisfied and the fiscal authority moves taxes in order to keep debt on a stable path: $\psi_{\pi, \xi_{t}^{s p}}>1$ and $\delta_{b, \xi_{t}^{s p}}>\beta^{-1}-1$. This last condition guarantees that the coefficient $\beta^{-1}-\delta_{b, \xi_{t}^{s p}}$ is smaller than one, so that debt is mean reverting. Therefore, we can think of fiscal policy as passive to the extent that it passively accommodates the behavior of the monetary authority ensuring debt stability. The second determinacy region, Passive Monetary/Active Fiscal $(\mathrm{PM} / \mathrm{AF})$, is less familiar and corresponds to the case in which the fiscal authority is not committed to stabilizing the process for debt: $\delta_{b, \xi_{t}^{s p}}<\beta^{-1}-1$. Now it is the monetary authority that passively accommodates the behavior of the fiscal authority, disregarding the Taylor principle and allowing inflation to move in order to stabilize the process for debt: $\psi_{\pi, \xi_{t}^{s p}}<1$. Under this regime, even in the absence of distortionary taxation, shocks to transfers can have an impact on the macroeconomy as agents understand that they will not be followed by future offsetting changes in the fiscal variables. Finally, when both authorities are active (AM/AF) no stationary equilibrium exists, whereas when both of them are passive $(\mathrm{PM} / \mathrm{PF})$ the economy is subject to multiple equilibria. ${ }^{4}$

\footnotetext{
${ }^{4}$ Following Woodford (1995), economists sometimes refer to the AM/PF regime with the term Ricardian, while the term non-Ricardian is used for the PM/AF regime. However, this straightforward one-to-one mapping between the policy mix and the terminology introduced by Woodford is possible only when assuming that agents are not aware of regime changes.
} 
In applied work, a lot of attention has been devoted to the AM/PF determinacy region and to the problem of indeterminacy (see Clarida, Gali, and Gertler (2000), Lubik and Schorfheide (2004), Coibion and Gorodichenko (2011), and Bhattarai, Lee, and Park (2012), among others). Instead, in this paper, we are interested in investigating the role that the lack of fiscal discipline has played in the evolution of the macroeconomy in the past sixty years. Therefore, our model allows for recurrent changes from an $\mathrm{AM} / \mathrm{PF}$ regime to a $\mathrm{PM} / \mathrm{AF}$ regime. The implicit assumption is that over different periods of time the balance of power between the monetary and fiscal authorities might have changed. We also allow for transitory periods during which both authorities are active. This allows us to capture situations in which one authority might try to become the leading authority without the immediate accommodating behavior of the other. Such a regime combination implies non-existence of a stationary equilibrium when in a fixed coefficient environment, while when allowing for regime changes its properties crucially depend on agents' beliefs about the authority that will eventually prevail.

Summarizing, we allow for a total of three policy regimes (PM/AF, AM/AF, and AM/PF) and two volatility regimes. We assume the following transition matrices:

$$
H^{s p}=\left[\begin{array}{ccc}
H_{11}^{s p} & H_{12}^{s p} & 0 \\
1-H_{11}^{s p} & H_{22}^{s p} & 1-H_{33}^{s p} \\
0 & H_{32}^{s p} & H_{33}^{s p}
\end{array}\right], H^{v o}=\left[\begin{array}{cc}
H_{11}^{v o} & 1-H_{22}^{v o} \\
1-H_{11}^{s p} & H_{22}^{v o}
\end{array}\right]
$$

We also experimented with a full transition matrix $H^{s p}$, with no noticeable change in the results, but a significant increase in the computational time. Considering more than three policy regimes and at the same time allowing for stochastic volatility proved to be computationally challenging. Given the importance of modeling stochastic volatility when studying the possibility of structural changes, we settled on this specification with three policy regimes that also emerged from some previous work (see Bianchi (2012)).

\subsection{Solving and estimating the MS-DSGE model}

The technology process $A_{t}$ is assumed to have a unit root. The model is then rescaled and linearized around the unique steady state (note that regime changes do not affect the steady state). We employ the solution algorithm proposed by Farmer, Waggoner, and Zha (2011). The authors show that when a solution exists, it can be characterized as a regime-switching vector autoregression, of the kind studied by Hamilton (1989), Chib (1996), and Sims and Zha (2006):

$$
S_{t}=T\left(\xi_{t}^{s p}, \theta^{s p}, H^{s p}\right) S_{t-1}+R\left(\xi_{t}^{s p}, \theta^{s p}, H^{s p}\right) Q\left(\xi_{t}^{v o}, \theta^{v o}\right) \varepsilon_{t}
$$

where $\theta^{s p}, \theta^{v o}$, and $S_{t}$ are vectors that contain the structural parameters, the stochastic volatilities, and all the variables of the model, respectively.

It is worth emphasizing that the law of motion of the model depends on the structural parameters 
$\left(\theta^{s p}\right)$, the regime in place $\left(\xi_{t}^{s p}\right)$, and the probability of moving across regimes $\left(H^{s p}\right)$. This means that what happens under one regime does not only depend on the structural parameters describing that particular regime but also on what agents expect is going to happen under alternative regimes and on how likely it is that a regime change will occur in the future (see also Davig and Leeper (2007)). In other words, agents' beliefs matter for the law of motion governing the economy.

The law of motion (6) is combined with a system of observation equations. The likelihood is computed with the modified Kalman filter described in Kim and Nelson (1999) and then combined with a prior distribution for the parameters to obtain the posterior. As a first step, a block algorithm is used to find the posterior mode, while a Metropolis algorithm is used to draw from the posterior distribution. Please refer to Appendix B and Bianchi (2013b) for more details.

\section{Estimates}

We include seven observables spanning the sample 1954:Q4-2009:Q3: real GDP growth, annualized GDP deflator inflation, FFR, annualized debt-to-GDP ratio on a quarterly basis, federal tax revenues to GDP ratio, federal expenditure to GDP ratio, and a transformation of government purchases to GDP ratio. Appendix $\mathrm{C}$ describes the dataset in detail.

\subsection{Parameters estimates and regime probabilities}

Table 2 reports priors and posterior parameter estimates. The priors for the parameters that do not move across regimes are in line with previous contributions in the literature and are relatively loose. As for the parameters of the Taylor rule, the prior for the autoregressive component is symmetric across regimes, whereas we have chosen asymmetric and truncated priors for the responses to inflation and the output gap in line with the theoretical restrictions outlined in Subsection 2.2: Under Regime 1 , monetary policy is passive, whereas under Regime 2 and Regime 3, monetary policy is active. In a similar way, the priors for the response of taxes to government debt are asymmetric across the two regimes: Under Regime 1 and Regime 2, this parameter is restricted to zero, whereas under Regime 3 it is expected to be fairly large. Overall, these priors imply that Regime 1, 2, and 3 belong to the $\mathrm{PM} / \mathrm{AF}, \mathrm{AM} / \mathrm{AF}$, and $\mathrm{AM} / \mathrm{PF}$ regions, respectively. In order to separate the short and long term components of government expenditure we restrict the persistence of the long term component $\rho_{e^{L}}=.99$ and the standard deviation of its innovations $\sigma_{e^{L}}=.1 \% .^{5}$ Finally, we fix the discount factor $\beta$ to .9985 , and the average maturity to 5 years (this is controlled by the parameter $\rho$ ). ${ }^{6}$

Regarding the parameters of the Taylor rule, under the AM/PF and AM/AF regimes the Federal

\footnotetext{
${ }^{5}$ This choice imposes a constraint on the amount of macroeconomic volatility that can be explained by the long term component. Our results are confirmed when removing this constraint.

${ }^{6}$ We evaluate the parameters' identification strength for the AM/PF and PM/AF regimes, using fixed coefficients methods developed in Iskrev $(2010 \mathrm{a}, \mathrm{b})$. We find that all parameters are identified in both regimes along a wide range of the prior support and that the fiscal parameters are more strongly identified in the PM/AF regime. We report details in the online technical appendix.
} 


\begin{tabular}{|c|c|c|c|c|c|c|c|}
\hline & Mode & Mean & $5 \%$ & $95 \%$ & Type & Mean & Std Dev \\
\hline$\psi_{\pi, P M}$ & (20.4991 & "0.5343 & 然.3726 & (20.7082 & $\overline{c G}$ & 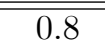 & 0.3 \\
\hline$\psi_{\pi, A M}$ & 2.7372 & 2.6787 & 1.9586 & 3.3946 & $N$ & 2.5 & 0.5 \\
\hline$\psi_{y, P M}$ & 0.1520 & 0.1412 & 0.0682 & 0.2160 & $G$ & 0.15 & 0.1 \\
\hline$\psi_{y, A M}$ & 0.7037 & 0.6432 & 0.3976 & 0.9875 & $G$ & 0.4 & 0.2 \\
\hline$\rho_{R, P M}$ & 0.6565 & 0.7480 & 0.6225 & 0.8427 & $B$ & 0.5 & 0.2 \\
\hline$\rho_{R, A M}$ & 0.9100 & 0.9027 & 0.8654 & 0.9350 & $B$ & 0.5 & 0.2 \\
\hline$\delta_{b, A F}$ & 0 & - & - & - & $F$ & - & - \\
\hline$\delta_{b, P F}$ & 0.0609 & 0.0636 & 0.0375 & 0.0955 & $G$ & 0.07 & 0.02 \\
\hline$\rho_{\tau, A F}$ & 0.8202 & 0.8193 & 0.7332 & 0.8907 & $B$ & 0.5 & 0.2 \\
\hline$\rho_{\tau, P F}$ & 0.9844 & 0.9803 & 0.9668 & 0.9901 & $B$ & 0.5 & 0.2 \\
\hline$H_{11}^{s p}$ & 0.9622 & 0.9656 & 0.9277 & 0.9958 & Dir & 0.96 & 0.03 \\
\hline$H_{22}^{s p}$ & 0.3502 & 0.4030 & 0.2094 & 0.6402 & Dir & 0.50 & 0.17 \\
\hline$H_{33}^{s p}$ & 0.9945 & 0.9911 & 0.9839 & 0.9961 & Dir & 0.96 & 0.03 \\
\hline$H_{12}^{s p}$ & 0.6236 & 0.5357 & 0.2119 & 0.7402 & Dir & 0.25 & 0.14 \\
\hline$\delta_{y}$ & 0.3504 & 0.3482 & 0.1879 & 0.5284 & $N$ & 0.2 & 0.2 \\
\hline$\delta_{e}$ & 0.3677 & 0.2806 & 0.0791 & 0.4467 & $N$ & 0.5 & 0.25 \\
\hline$\iota_{y}$ & 0.1008 & 0.1016 & -0.2318 & 0.4271 & $N$ & 0.1 & 0.2 \\
\hline$\phi_{y}$ & -0.3933 & -0.4053 & -0.4854 & -0.3375 & $N$ & 0.1 & 0.2 \\
\hline$\varsigma$ & 0.2373 & 0.1712 & 0.0370 & 0.3319 & $B$ & 0.5 & 0.25 \\
\hline$\Phi$ & 0.5524 & 0.5961 & 0.4771 & 0.7228 & $B$ & 0.5 & 0.25 \\
\hline$\kappa$ & 0.0050 & 0.0054 & 0.0034 & 0.0079 & $G$ & 0.3 & 0.15 \\
\hline$\rho_{\chi}$ & 0.9968 & 0.9955 & 0.9915 & 0.9983 & $B$ & 0.5 & 0.2 \\
\hline$\hat{\rho_{a}}$ & 0.4535 & 0.4054 & 0.1760 & 0.6230 & $B$ & 0.5 & 0.2 \\
\hline$\rho_{d}$ & 0.9442 & 0.9313 & 0.8881 & 0.9579 & $B$ & 0.5 & 0.2 \\
\hline$\rho_{e^{S}}$ & 0.4351 & 0.4147 & 0.3070 & 0.5273 & $B$ & 0.2 & 0.05 \\
\hline$\rho_{\mu}$ & 0.0524 & 0.0881 & 0.0215 & 0.1833 & $B$ & 0.5 & 0.2 \\
\hline$\rho_{t p}$ & 0.0507 & 0.0741 & 0.0226 & 0.1443 & $B$ & 0.5 & 0.2 \\
\hline $100 \pi$ & 0.5069 & 0.4886 & 0.4201 & 0.5569 & $N$ & 0.5 & 0.05 \\
\hline $100 \ln (\gamma)$ & 0.3938 & 0.4027 & 0.3391 & 0.4651 & $N$ & 0.42 & 0.05 \\
\hline$b^{m}$ & 0.8823 & 0.9073 & 0.7826 & 1.0368 & $N$ & 1 & 0.1 \\
\hline$g$ & 1.0846 & 1.0861 & 1.0760 & 1.0961 & $N$ & 1.08 & 0.04 \\
\hline$\tau$ & 0.1735 & 0.1738 & 0.1708 & 0.1769 & $N$ & 0.18 & 0.005 \\
\hline $100 \sigma_{R, 1}$ & 0.0983 & 0.1115 & 0.0928 & 0.1295 & $I G$ & 0.5 & 0.5 \\
\hline $100 \sigma_{R, 2}$ & 0.4087 & 0.4574 & 0.3593 & 0.5759 & $I G$ & 0.5 & 0.5 \\
\hline $100 \sigma_{\chi, 1}$ & 2.0289 & 2.0201 & 1.7196 & 2.3706 & $I G$ & 1 & 1 \\
\hline $100 \sigma_{\chi, 2}$ & 4.4722 & 4.8008 & 3.8735 & 5.9637 & $I G$ & 1 & 1 \\
\hline $100 \sigma_{a, 1}$ & 0.4822 & 0.5436 & 0.3743 & 0.7533 & $I G$ & 1 & 1 \\
\hline $100 \sigma_{a, 2}$ & 0.4210 & 0.5318 & 0.3361 & 0.8155 & $I G$ & 1 & 1 \\
\hline $100 \sigma_{\tau, 1}$ & 0.3279 & 0.3465 & 0.3088 & 0.3890 & $I G$ & 2 & 2 \\
\hline $100 \sigma_{\tau, 2}$ & 0.8678 & 0.9066 & 0.7377 & 1.1180 & $I G$ & 2 & 2 \\
\hline $100 \sigma_{d, 1}$ & 6.4958 & 6.4134 & 5.4309 & 7.5891 & $I G$ & 10 & 2 \\
\hline $100 \sigma_{d, 2}$ & 10.8225 & 11.4179 & 9.0801 & 14.2862 & $I G$ & 10 & 2 \\
\hline $100 \sigma_{e^{S}, 1}$ & 0.3069 & 0.3041 & 0.2710 & 0.3424 & $I G$ & 2 & 2 \\
\hline $100 \sigma_{e^{S}, 2}$ & 0.6224 & 0.6649 & 0.5266 & 0.8393 & $I G$ & 2 & 2 \\
\hline $100 \sigma_{t p, 1}$ & 2.9593 & 3.0096 & 2.7233 & 3.3243 & $I G$ & 1 & 1 \\
\hline $100 \sigma_{t p, 2}$ & 3.6702 & 4.0379 & 3.1491 & 5.0889 & $I G$ & 1 & 1 \\
\hline $100 \sigma_{\mu, 1}$ & 0.1853 & 0.1977 & 0.1733 & 0.2242 & $I G$ & 1 & 1 \\
\hline $100 \sigma_{\mu, 2}$ & 0.4216 & 0.4441 & 0.3471 & 0.5645 & $I G$ & 1 & 1 \\
\hline$H_{11}^{v o}$ & 0.9265 & 0.9295 & 0.8922 & 0.9603 & Dir & 0.83 & 0.10 \\
\hline$H_{22}^{v o}$ & 0.7295 & 0.7216 & 0.5852 & 0.8430 & Dir & 0.83 & 0.10 \\
\hline
\end{tabular}

Table 2: Posterior modes, means, and 90\% error bands of the model parameters. For the structural parameters Regimes 1, 2, and 3 correspond to $\mathrm{PM} / \mathrm{AF}, \mathrm{AM} / \mathrm{AF}$, and $\mathrm{AM} / \mathrm{PF}$, respectively. For the stochastic volatilities Regime 1 and Regime 2 are the Low and High volatility regimes, respectively 

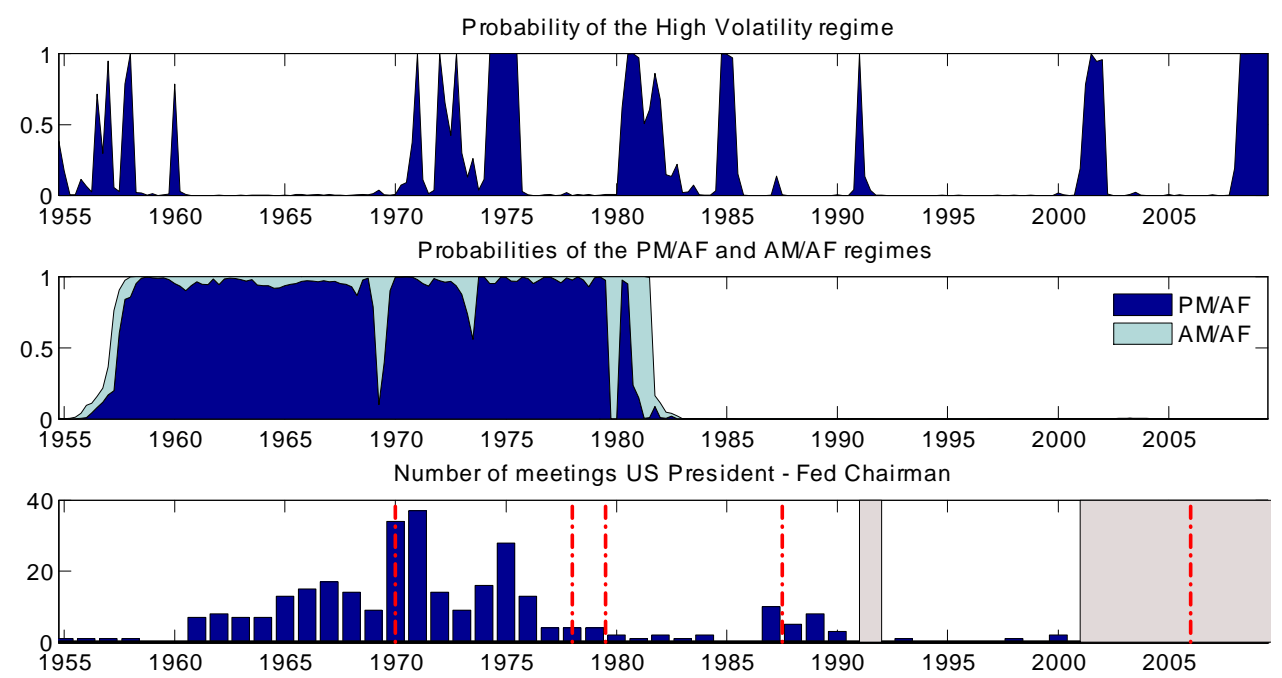

Figure 2: Regime probabilities at the posterior mode. Top panel: Probability of the High Volatility regime. Middle panel: Probabilities of the PM/AF and AM/AF regimes. Lower panel: Number of meetings between US Presidents and Fed Chairmen. The light gray areas correspond to missing data.

Funds rate reacts strongly to both inflation and the output gap. The opposite occurs under the $\mathrm{PM} / \mathrm{AF}$ regime. It is worth pointing out that the posterior estimates for the coefficients of the Taylor rule are relatively tight and the truncated priors are not binding. Under the PM/AF and AM/AF regimes the response of taxes to debt is restricted to zero, while under the $\mathrm{AM} / \mathrm{PF}$ regime it turns out to be significantly larger than the threshold value described in Subsection $2.2\left(\beta^{-1}-1=.0015\right)$. As for the other structural parameters, it is worth pointing out that the parameter $\varsigma$ capturing the level of indexation with respect to lagged inflation is much smaller than what is generally obtained in the literature. Section 5 will illustrate that regime changes can account for breaks in the persistence of inflation.

In a MS-DSGE the estimates of the transition matrix of the structural parameters are determined by the realized regime sequence, but also by the model dynamics across the different regimes. It is therefore useful to review the properties of the estimated transition matrix. Both the AM/PF regime and the $\mathrm{PM} / \mathrm{AF}$ regime are quite persistent, while under the $\mathrm{AM} / \mathrm{AF}$ regime there is a very high probability of moving to the $\mathrm{PM} / \mathrm{AF}$ regime. The estimated parameter values have three important implications that will be key to understand the results of this paper. First, the system spends a lot of time under one of the two polar cases, the $\mathrm{AM} / \mathrm{PF}$ and $\mathrm{PM} / \mathrm{AF}$ regimes. Second, when fiscal policy is active, monetary policy is generally passive, with a few short lasting intervals during which both policies are active. On the contrary, when the $\mathrm{AM} / \mathrm{PF}$ regime is in place, movements to the $\mathrm{AM} / \mathrm{AF}$ are expected to be followed by the $\mathrm{PM} / \mathrm{AF}$ regime, not by a return to the AM/PF regime. Finally, even if the AM/PF regime is the most persistent regime, the ergodic probability of being in the $\mathrm{PM} / \mathrm{AF}$ regime is 0.74 , while the ergodic probability of the $\mathrm{AM} / \mathrm{PF}$ regime is 0.21 , implying that the $\mathrm{PM} / \mathrm{AF}$ regime is the most recurrent one.

The first panel of Figure 2 reports the probability of the High Volatility regime. This captures some key macroeconomic events, such as the 1974 oil shock, the high volatility of the FFR during the 
reserve targeting period of the early '80s, the 1991 recession, the 2001 recession and subsequent Bush's tax cuts, and the 2008 financial crisis. It is worth emphasizing that the pattern for the high volatility regime looks somehow different from the one found in studies that focus exclusively on changes in the conduct of monetary policy. Section 5 will illustrate that changes in the monetary/fiscal policy mix is in itself an important source of macroeconomic volatility.

The second panel of Figure 2 shows the smoothed probabilities assigned to the three policy regimes. Active fiscal policy turns out to be in place for a large part of the first half of the sample. Over the same period of time, monetary policy is generally passive, even if we observe some probability of switches to the active regime, most noticeably at the end of the '60s. The estimates capture remarkably well the change in the conduct of monetary policy that occurred with the appointment of Paul Volcker in August '79. Monetary policy becomes active, while fiscal policy stays active. Then we observe a brief return to the $\mathrm{PM} / \mathrm{AF}$ regime, followed again by a period during which both authorities behave according to active rules. It is only at the end of 1981 that fiscal policy accommodates the switch in the conduct of monetary policy moving from the active to the passive policy rule. The $\mathrm{AM} / \mathrm{PF}$ policy mix has been in place since then.

We will explicitly link the timing of the regime changes to historical accounts of the interaction between the fiscal and monetary authorities in Section 6, once the consequences of changes in the monetary/fiscal policy mix will be well understood. In the meantime, it is enough to highlight that these results point toward a substantial change in the balance of power between the monetary and fiscal authorities. As suggestive evidence, the lower panel of Figure 2 reports the number of meetings between the US President and the Fed Chairman over a year. ${ }^{7}$ It is quite interesting that such meetings were substantially more frequent before the appointment of Volcker than afterwards. The average number of meetings per year was 14.87 over the period $1964-1979$, while it dropped to 2 over the period $1980-2001$.

\subsection{Impulse response analysis}

This section analyzes in detail how changes in policymakers' behavior or in agents' beliefs affect the propagation of the shocks through the economy. In the first subsection, we focus on the difference across regimes, while in the second and third subsections we first emphasize the role of agents' beliefs in determining the properties of the $\mathrm{AM} / \mathrm{PF}$ and $\mathrm{PM} / \mathrm{AF}$ regimes and then we analyze the effects of a transition from the $\mathrm{PM} / \mathrm{AF}$ regime to the $\mathrm{AM} / \mathrm{AF}$ regime in order to shed light on the events of the early ' 80 s.

\footnotetext{
${ }^{7}$ We thank Fernando Martin for sharing these data with us (see Martin (2012)). The data are obtained from the Agenda of each president which is available at the respective presidential library. At this stage, the data for 1991 and 1992 and after 2000 are not available.
} 

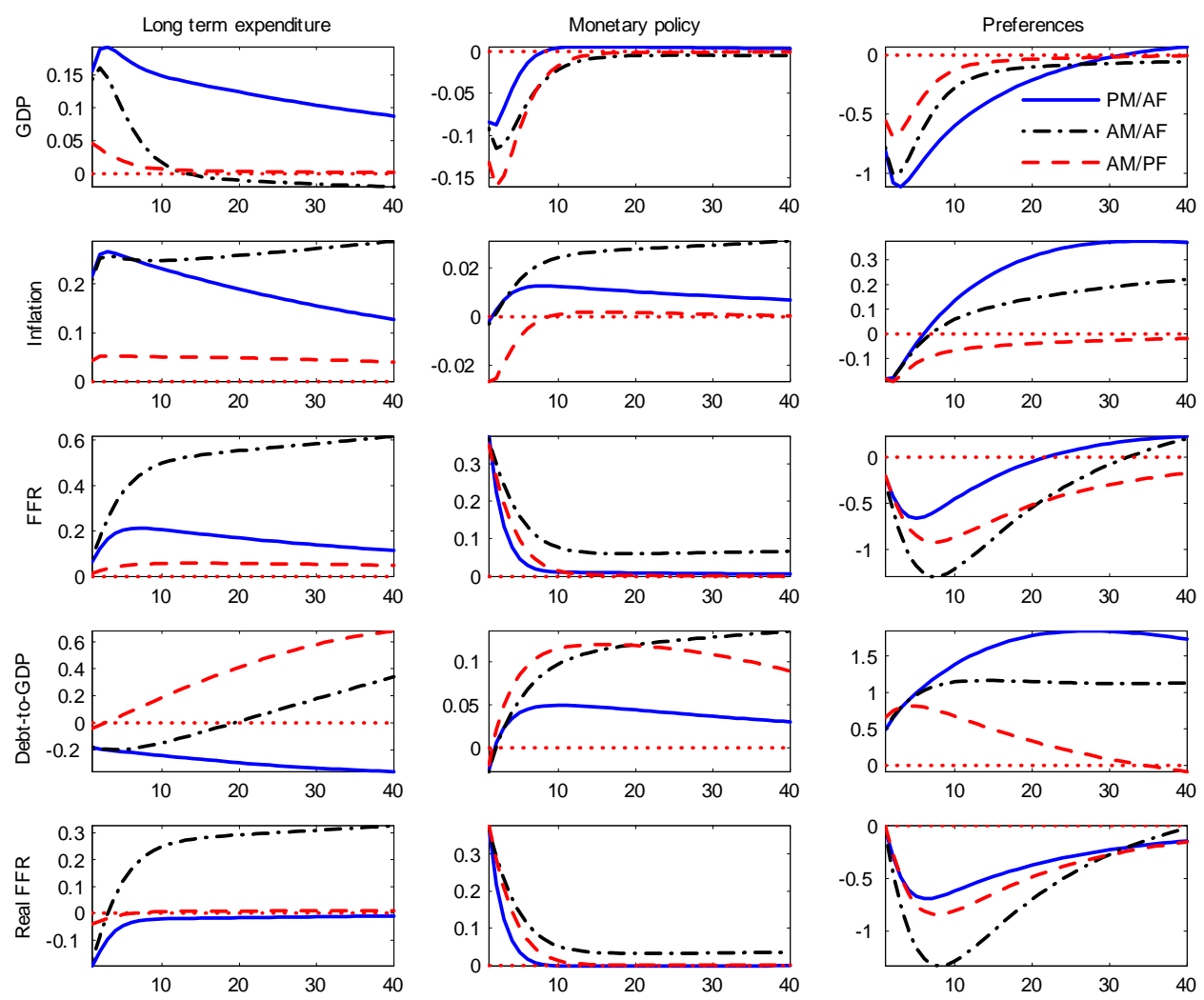

Figure 3: The three columns report the impulse responses to an increase in the long term component of expenditure, a monetary policy shock, and a negative preference shock, for each of the three policy regimes identified in the estimates: $\mathrm{PM} / \mathrm{AF}, \mathrm{AM} / \mathrm{AF}$, and $\mathrm{AM} / \mathrm{PF}$.

\subsubsection{Actual impulse responses}

Figure 3 reports the responses of GDP, inflation, FFR, debt-to-GDP, and the real FFR to shocks to long term expenditure, the FFR, and preferences for each of the three regimes identified in the estimates: PM/AF (solid blue line), AM/AF (dashed-dotted black line), and AM/PF (dashed red line). The impulse responses are computed conditional on being in a particular regime for 40 quarters. However, the implied law of motion reflects the possibility of regime changes.

Government expenditure, Inflation, and Agents' Beliefs. The first column reports the responses to a shock to the long term component of government expenditure. The difference between the $\mathrm{PM} / \mathrm{AF}$ and $\mathrm{AM} / \mathrm{PF}$ regime is particularly striking. Under the $\mathrm{PM} / \mathrm{AF}$ regime, agents anticipate that with high probability the increase in expenditure will not be fully covered by future fiscal adjustments. This determines an increase in inflation that is accommodated by the central bank. Given that the Taylor principle does not hold, we observe a prolonged period of negative real interest rates and an increase in output. These effects, combined with a decline in the price of long term bonds due to higher expected future short term interest rates, determine a drop in the debt-to-GDP ratio. Under the $\mathrm{AM} / \mathrm{PF}$ regime the increase in inflation is substantially smaller and generates only a modest increase in real activity. This is because, under the AM/PF regime the fiscal authority is committed to move taxes in order to cover the fiscal imbalance resulting from the increase in 
expenditure. However, the impact of the shock on inflation is not zero because agents are aware of the possibility of regime changes. Therefore, even if the fiscal authority is making the necessary fiscal adjustments today, there is always the possibility that in the future the economy will move back to the PM/AF regime. This result is in line with what was obtained by Davig and Leeper (2006) in a calibrated model and by Davig, Chung, and Leeper (2007) in an analytical example.

The AM/AF regime combines the properties of the other two regimes. Given that from the $\mathrm{AM} / \mathrm{AF}$ regime the estimated probability of moving to the $\mathrm{PM} / \mathrm{AF}$ regime is very high, the increase in the long term component of expenditure determines an increase in inflation. However, under this regime, the central bank does not accommodate the increase in inflation and the FFR eventually rises. This determines a decline in real activity that in turn makes the fiscal burden even larger. As a result inflation keeps increasing, while output keeps declining.

The ability to control inflation. The second column of Figure 3 reports the responses to a monetary policy shock. Under all regimes, the Federal Reserve retains the ability to generate a recession and an initial decline in inflation. However, under the $\mathrm{PM} / \mathrm{AF}$ and $\mathrm{AM} / \mathrm{AF}$ regimes, the monetary policy shock backfires. This is because the increase in the real cost of debt and the associated recession make the debt burden larger, calling for an increase in inflation. This "stepping on a rake" effect (Sims, 2011) implies that the central bank's ability to control inflation is lost the moment that its actions are not adequately supported by the fiscal authority. The response of the debt-to-GDP ratio is also substantially different across the two regimes: Under the AM/PF regime, the ratio increases quickly due to the decline in output and high real interest rates, whereas under the $\mathrm{PM} / \mathrm{AF}$ regime we observe only a modest increase, due to the slowdown of the economy, followed by a smooth decline as a consequence of the high inflation.

An economic slowdown. The last column of Figure 3 considers the consequences of an economic slowdown caused by a negative preference shock. Across all regimes such a shock determines a reduction in real activity and an initial decline in inflation, in line with standard predictions of newKeynesian models. However, when the PM/AF and AM/AF regimes are in place, this initial decline is soon followed by a rise in inflation. This is because the recession determines an increase of the fiscal burden that is inflationary only when agents expect to spend many periods out of the AM/PF regime.

\subsubsection{Monetary/Fiscal Policy Mix and Agents' Beliefs}

To highlight the role played by agents' beliefs in the propagation of fiscal disturbances, we compare the benchmark impulse responses with two counterfactual scenarios. In the first counterfactual scenario, we modify the transition matrix in a way to make the $\mathrm{AM} / \mathrm{PF}$ regime the most frequent policy mix. Specifically, conditional on leaving the AM/AF regime, the probability of moving to the $\mathrm{PM} / \mathrm{AF}$ regime is decreased by 60\%: $H_{12}^{s p}$ and $H_{32}^{s p}$ move from .6236 to .2494 and from .0262 to .4003,

respectively, while $H_{22}^{s p}$ is left unchanged. This implies that now policymakers are expected to spend a lot of time in the $\mathrm{AM} / \mathrm{PF}$ regime with only brief periods during which both policies are active. 

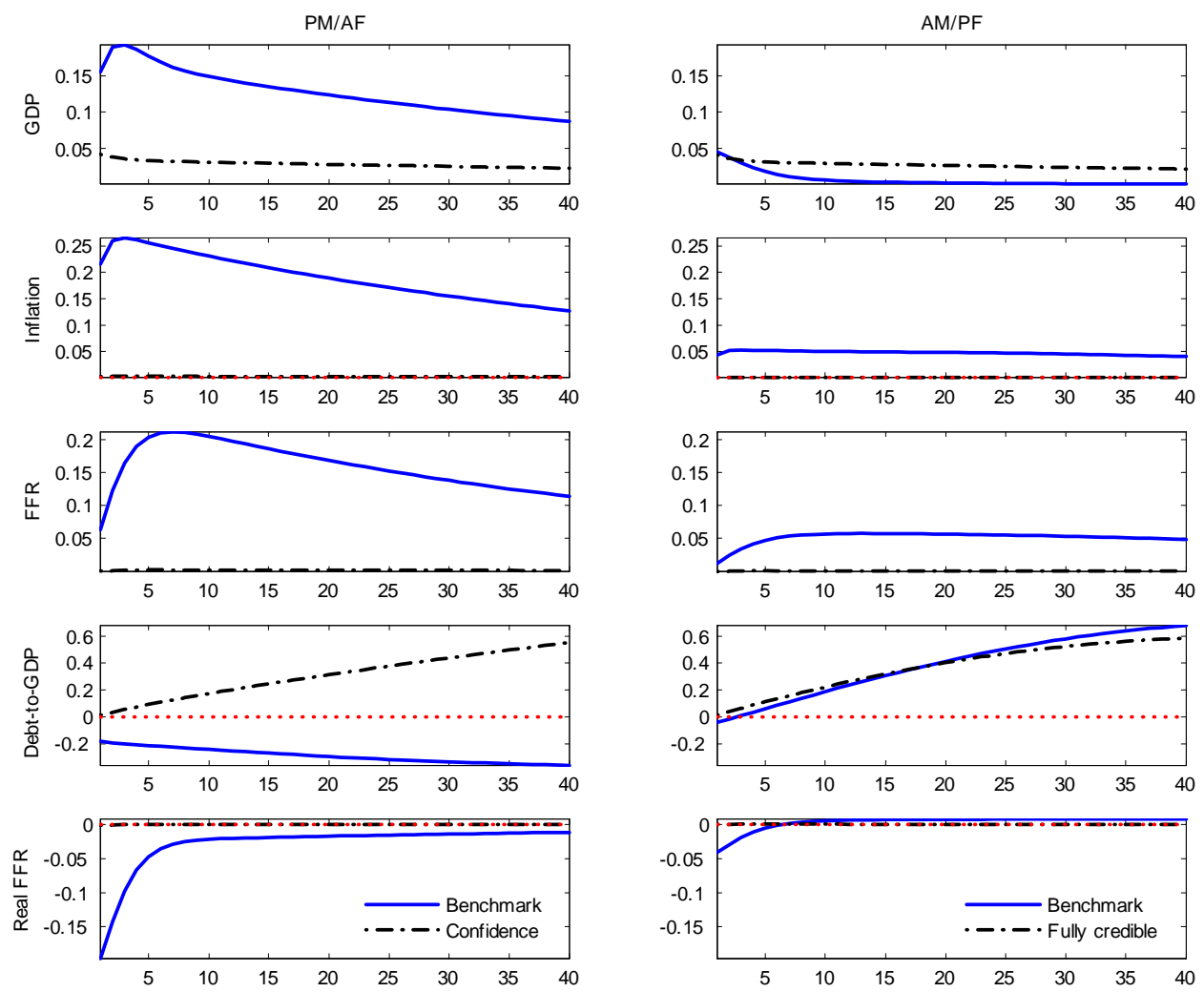

Figure 4: Actual and counterfactual impulse responses to an increase in the long term component of expenditure. The left hand side considers the benchmark PM/AF regime and the "confidence counterfactual" in which the AM/PF regime is the dominant regime. The right hand side considers the benchmark AM/PF regime and the "fully credible" counterfactual in which the $\mathrm{AM} / \mathrm{PF}$ regime is the only possible regime.

Once in a while from the $\mathrm{AM} / \mathrm{AF}$ regime they move to the $\mathrm{PM} / \mathrm{AF}$ regime, but given the estimated persistence of this regime, agents are in general confident about a return to the AM/PF regime. We denote this scenario Confidence counterfactual. In the second counterfactual scenario, we assume that the $\mathrm{AM} / \mathrm{PF}$ policy mix is the only possible one. We refer to this scenario as Fully credible $A M / P F$ regime. Notice that this case corresponds to the textbook version of the new-Keynesian model in which monetary policy always follows the Taylor principle.

The first column of Figure 4 considers the shock to the long term component of expenditure under the PM/AF policy mix under the benchmark case and the Confidence counterfactual. Notice that now the effect on inflation is absent. This is because agents are confident that the necessary fiscal adjustments will eventually be made. We still observe an increase in GDP, but this is simply due to the fact that the increase in expenditure also determines an increase in the amount of goods bought by the government. Given that this does not affect the output gap, the expansion in real activity is not inflationary. Finally, we do not observe the decline in the debt-to-GDP ratio and the prolonged period of low real interest rates that characterize the benchmark case.

The second column of Figure 4 considers the same shock under the benchmark AM/PF regime and the counterfactual Fully credible $A M / P F$. Notice that in this second case we do not observe any increase in inflation, in line with what is predicted by the textbook version of the new-Keynesian 

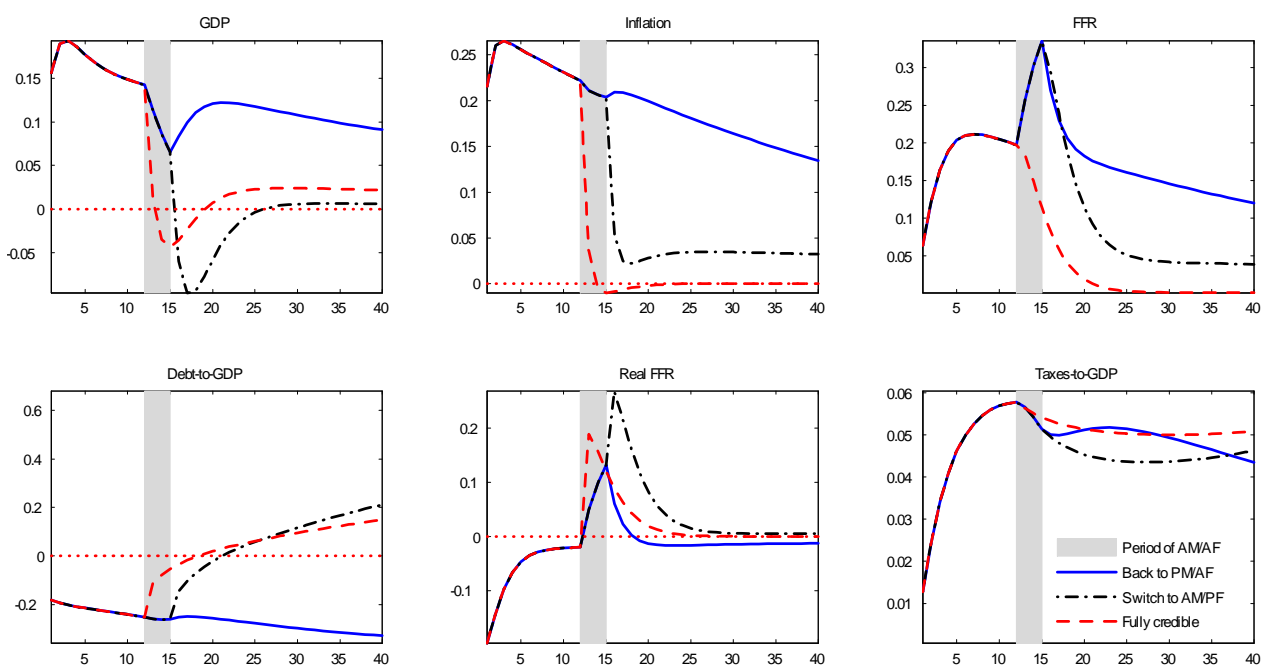

Figure 5: Impulse responses to a one standard deviation increase in the long term component of government expenditure that occurs under the $\mathrm{PM} / \mathrm{AF}$ regime. Three years after the shock we consider three different cases. Under the red dashed line policymakers immediately switch to the counterfactual Fully Credible AM/PF regime. Under the solid blue line, the economy moves to the $\mathrm{AM} / \mathrm{AF}$ regime, and after a year it returns to the $\mathrm{PM} / \mathrm{AF}$ regime. Instead, under the black dashed-dotted line, the economy again spends a year under the AM/AF, but then moves to the AM/PF regime.

model with no distortionary taxation. The increase in output is instead more pronounced. This is because under the benchmark case the central bank tries to fight the inflationary pressure that results from the fiscal shock. In the counterfactual scenario there is no need to do so, given that there is no rise in inflation and the output increase leaves the output gap substantially unchanged.

Finally, it is worth emphasizing that the response of the macroeconomy to an expenditure shock under the Confidence counterfactual $\mathrm{PM} / \mathrm{AF}$ regime is extremely similar to what is implied by the counterfactual Fully credible $A M / P F$ regime, even if the policy rules differ across the two regimes. In both cases, the increase in expenditure does not lead to inflation because agents expect that the necessary fiscal adjustments will be made. Given that taxation is non-distortionary, the difference in the timing of the fiscal adjustments does not affect the behavior of the macroeconomy. This result does not hold for all shocks and it illustrates an important point: Fiscal imbalances are inflationary whenever there is a lack of commitment to make the necessary fiscal adjustments.

\subsubsection{From PM/AF to AM/PF: A sudden disinflation}

In this subsection, we are interested in inspecting the mechanism behind the failed attempts to disinflate of the '70s and the successful disinflation of the early '80s. Furthermore, we will shed light on why these attempts were so costly in terms of output losses.

Figure 5 reports the responses of GDP, inflation, FFR, debt-to-GDP ratio, the real FFR, and tax revenues-to-GDP ratio to a one standard deviation increase in the long term component of government expenditure. The initial shock occurs under the PM/AF regime. Three years after the shock, we consider three different scenarios. In the first two, the economy moves to the AM/AF regime and spends a year under such a regime. After that, two different cases are considered. In 
the first scenario, solid blue line, policymakers return to the PM/AF regime. In the second case, black dashed-dotted line, policymakers move to the AM/PF regime. Finally, in the third scenario instead of entering the $\mathrm{AM} / \mathrm{AF}$ regime, policymakers immediately move to the $\mathrm{AM} / \mathrm{PF}$ policy mix and are able to convince agents that they will never leave such regime (red dashed line). This last case corresponds to a switch to the counterfactual Fully credible $A M / P F$ regime.

Several aspects of this simulation are worth emphasizing. The initial response of the macroeconomy coincides with what is described in the previous subsection: Agents expect that the increase in expenditure will not be followed by fiscal adjustments and as a result inflation and real activity increase. When policymakers move to the $\mathrm{AM} / \mathrm{AF}$ regime, the central bank is able to generate a sizeable contraction in real activity. However, the impact on inflation is minimal because agents expect a return to the $\mathrm{PM} / \mathrm{AF}$ regime with very high probability. Therefore, the implied sacrifice ratio, measured by the ratio between the cost of lower output and the gains in terms of lower inflation, is very high in this case.

If then policymakers switch back to the $\mathrm{PM} / \mathrm{AF}$ regime, inflation returns to a value that is higher than what would have been if the switch to the AM/AF regime had never occurred. This is because the fiscal burden has in the meantime increased due to the effect of the recession. If instead policymakers move to the $\mathrm{AM} / \mathrm{PF}$ regime, the economy experiences a sudden drop in inflation and a recession. Notice that the central bank's behavior is unchanged across the AM/AF and AM/PF regimes. Therefore, the drop in inflation is not due to a change in monetary policy, but to the change in the behavior of the fiscal authority that triggers a revision in agents' beliefs about the way the fiscal burden will be financed. Despite the sudden drop, inflation does not go all the way down to the steady state. Instead, it stabilizes around a positive value that reflects the possibility of a return to the PM/AF regime and the fact that the fiscal burden has not been fully reabsorbed yet. Given that monetary policy is now active, the central bank reacts more than one-to-one to inflation, determining a positive real interest rate that in turn pushes output below its own steady state. Notice that these dynamics are in line with the impulse responses shown in the first column of Figure 4.

It is important to emphasize that after the switch to the AM/PF regime the tax-to-GDP ratio declines with respect to the period that precedes the switch. This occurs for two reasons. First the economy experiences a contraction and our fiscal rule allows for automatic stabilizers. Second, even if now the fiscal authority is committed to increase taxes in order to cover the increase in expenditure, the debt-to-GDP ratio is below its steady state at the time of the regime change, implying that there is no need of an immediate increase in taxes. In other words, at the time of the switch, part of the debt burden has already been erased by inflation. It is only in the long run that the tax-to-GDP ratio starts to slowly increase in response to the increase in debt. In fact, when the economy moves to the $\mathrm{AM} / \mathrm{PF}$ regime, we observe a sudden reversal in the dynamics of the debt-to-GDP ratio. The increase is determined by the recession and the sudden increase in real interest rates, but a revaluation effect determined by the revision in the expected path for future short term interest rates contributes to the initial jump. If instead the economy returns to the PM/AF regime, the debt-to-GDP ratio keeps 
declining.

It is then instructive to compare this disinflation with what is implied by a switch to the Fully credible $A M / P F$ regime. First of all, inflation now drops immediately to the steady state. This is because agents are not concerned about the possibility of a return to the PM/AF regime. Consequently, there is no inflationary pressure to be fought by the central bank and as a result output does not experience the prolonged slowdown associated with the benchmark AM/PF regime. Notice that these different outcomes are not due to differences in the behavior of the fiscal authority. The fiscal rule is unchanged across the two simulations, except for the short period during which both policy authorities are active, as illustrated by the behavior of the tax-to-GDP ratio in the right lower-right panel of Figure 5. It is also interesting to notice how the increase in the debt-to-GDP ratio is faster under the benchmark AM/PF regime than under the Fully credible AM/PF regime. This reflects the larger decline in real activity and the increase in the cost of financing debt caused by the possibility of a return to the $\mathrm{PM} / \mathrm{AF}$ regime.

Summarizing, several lessons can be drawn from these simulations. Following an increase in the fiscal burden, a short period of active monetary and active fiscal policies lead to an output contraction, but not to a visible change in inflation. This is because the change in monetary policy is not supported by a change in fiscal policy and agents expect that the fiscal authority will eventually prevail. It is only in the moment that the fiscal authority accommodates the behavior of the monetary authority that inflation drops. However, the fact that the fiscal burden has not been completely reabsorbed implies inflationary pressure. In an attempt to contrast such inflationary pressure the central bank determines a prolonged slowdown in real activity. These dynamics would completely disappear and inflation would immediately go back to the steady state if agents were convinced that policymakers will never return to the PM/AF regime or if the fiscal burden were largely reabsorbed at the moment of the switch. These results will be very important to understand the counterfactual simulations of the next section.

\section{Counterfactual analysis}

One of the most interesting exercises that can be implemented when working with models that allow for regime changes consists of simulating what would have happened under alternative scenarios. Structural shocks are backed-out using the estimates and then used to simulate an economy subject to the same disturbances, but with interesting changes in the way policymakers behave. This kind of analysis is even more meaningful in the context of the MS-DSGE model employed in this paper. First of all, like a standard DSGE model, the MS-DSGE can be re-solved for alternative policy rules: The entire law of motion changes in a way that is consistent with the new assumptions around the behavior of the two authorities. Furthermore, the solution depends on agents' beliefs. This means that beliefs counterfactuals, as introduced in Bianchi (2013b), can be explored: In these counterfactuals agents are endowed with specific beliefs about alternative scenarios. 

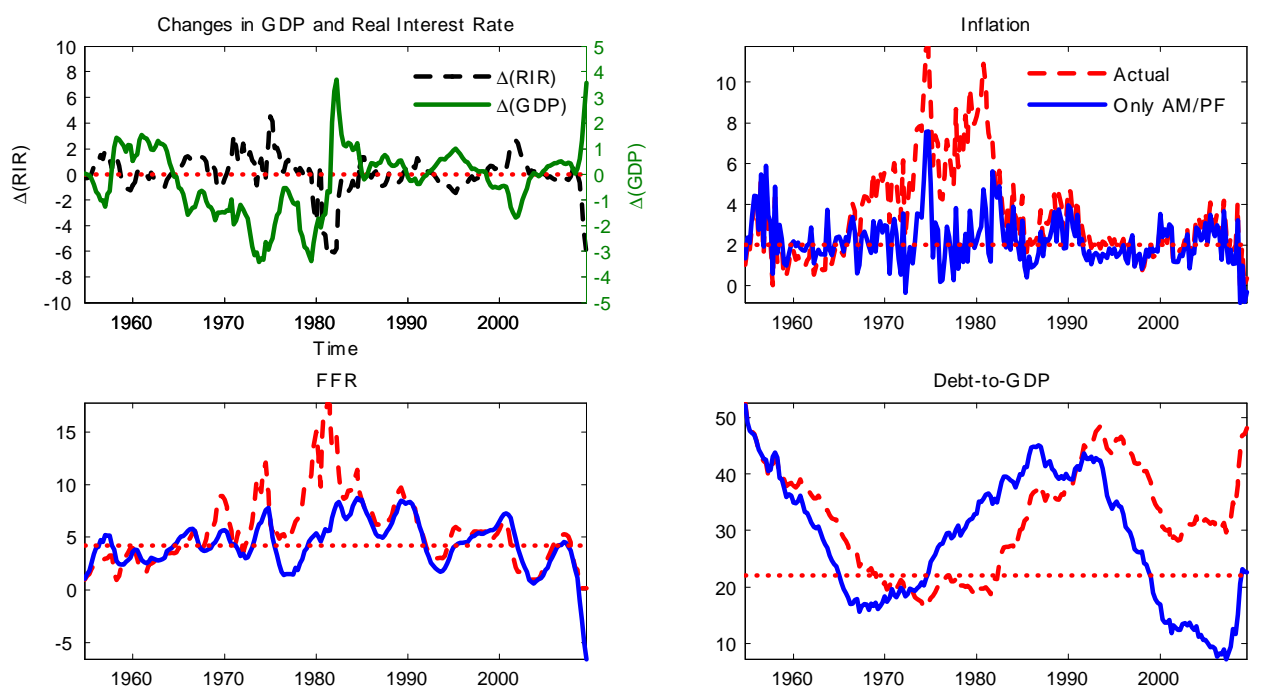

Figure 6: The Great Inflation: Fully credible $A M / P F$. Counterfactual simulation in which non-policy shocks are left unchanged and the $\mathrm{AM} / \mathrm{PF}$ regime is assumed to be the only possible one. The first panel reports the change in the real interest rate and GDP. The remaining three panels report actual and counterfactual series for inflation, FFR, and debt-to-GDP ratio.

In what follows, we will make use of both traditional and beliefs counterfactuals to establish the following results. First, if the $\mathrm{AM} / \mathrm{PF}$ had been in place over the entire sample, we would not have observed the rise in trend inflation, from which we conclude that the prevalence of the PM/AF regime during the '60s and the '70s is important to understand the Great Inflation. Second, if during the '70s agents had been confident about moving to the AM/PF regime, the Great Inflation would not have occurred. Third, in the context of our model, changes in policymakers' behavior, not a series of shocks, explains the dynamics of inflation, debt, output and real interest rates during the early '80s.

\subsection{The Great Inflation}

What caused the rise in trend inflation in the '70s? A series of adverse shocks, policymakers' behavior, or a combination of the two? In order to answer these questions we simulate an economy in which the sequence of non-policy shocks is kept unchanged, while policymakers are assumed to behave according to the $\mathrm{AM} / \mathrm{PF}$ regime over the entire sample. Consistently with this assumption, we assume that agents regard the $\mathrm{AM} / \mathrm{PF}$ regime as the only possible one. This corresponds to the case of the Fully credible $A M / P F$ regime described above. Notice that this simulation implies a change in both policymakers' behavior and agents' beliefs.

Figure 6 shows the change in GDP and real interest rates and the actual (dashed red line) and counterfactual series (solid blue line) for inflation, FFR, and debt-to-GDP ratio. It is apparent that under these assumptions the economy would have experienced a substantially lower level of inflation: While the high frequency movements, such as the one associated with the oil crises of the '70s, are substantially unaffected, the economy would not have experienced the rise in trend inflation. Real interest rates would have been substantially higher in the '70s, while they would not have increased 

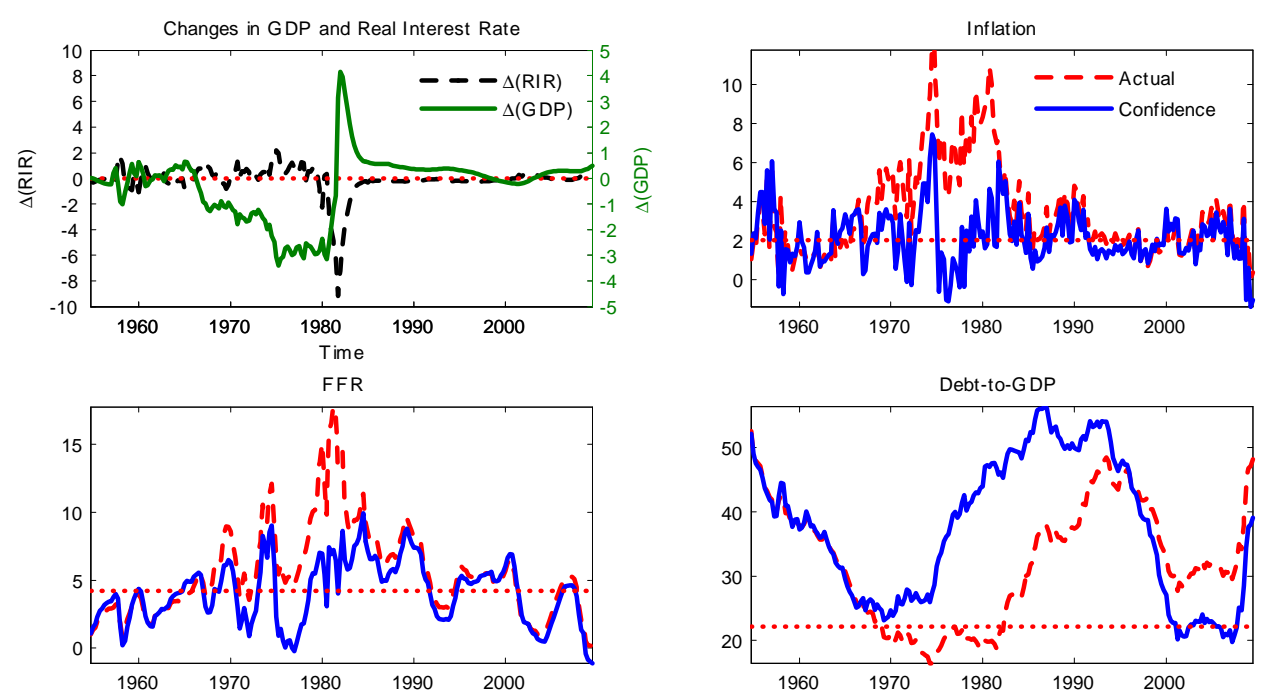

Figure 7: The Great Inflation: Confidence. Counterfactual simulation in which all shocks and regime sequences are left unchanged, but agents are confident that a switch to the AM/PF regime will eventually occur. The first panel reports the change in the real interest rate and GDP. The remaining three panels report actual and counterfactual series for inflation, FFR, and debt-to-GDP ratio.

sharply during the '80s. Symmetrically, during the first half of the sample output losses would have been relatively large, with a peak of around 3.5\% in correspondence of the two oil crises. However, given that inflation would not have experienced the run-up observed in the data, the economy would have been able to avoid the painful recession associated with the Volcker disinflation. The debtto-GDP ratio would have been slightly smaller during the '60s, but it would have increased rapidly during the '70s, despite passive fiscal policy, because of lower growth and higher real interest rates. ${ }^{8}$

Based on the previous counterfactual simulation, we can conclude that if policymakers' behavior had been different, the Great Inflation of the '70s would not have occurred. It is then interesting to understand, for given policymakers' behavior, what role agents' beliefs played in the rise of inflation. This second counterfactual asks what would have happened if since 1955 agents had been confident about the possibility of moving to the AM/PF equilibrium. Specifically, we keep the estimated shocks and regime sequence unchanged, but modify the transition matrix of the policy regimes as in the Confidence counterfactual described in Subsection 3.2.2. It is worth pointing out that this is a pure beliefs counterfactual, given that policymakers' behavior is left unchanged, while agents' beliefs are modified.

Figure 7 contains the results. During the '70s inflation would have moved around the steady state without the persistent increase in trend inflation. Once again, real interest rates would have been higher in the '60 and '70s, and substantially lower in the early 80s, showing a much smoother path with respect to the data. Symmetrically, output would have been substantially lower in the '70s, but the economy would have avoided the deep recession of the early '80s. Finally, the series for debt

${ }^{8}$ Appendix D shows that similar results are obtained when the counterfactual Fully credible AM/PF regime is replaced with the benchmark $\mathrm{AM} / \mathrm{PF}$ regime. In this second case, agents do not regard the $\mathrm{AM} / \mathrm{PF}$ regime as the only possible one. We report results for the Fully credible AM/PF regime because they are more robust to the Lucas' critique. 

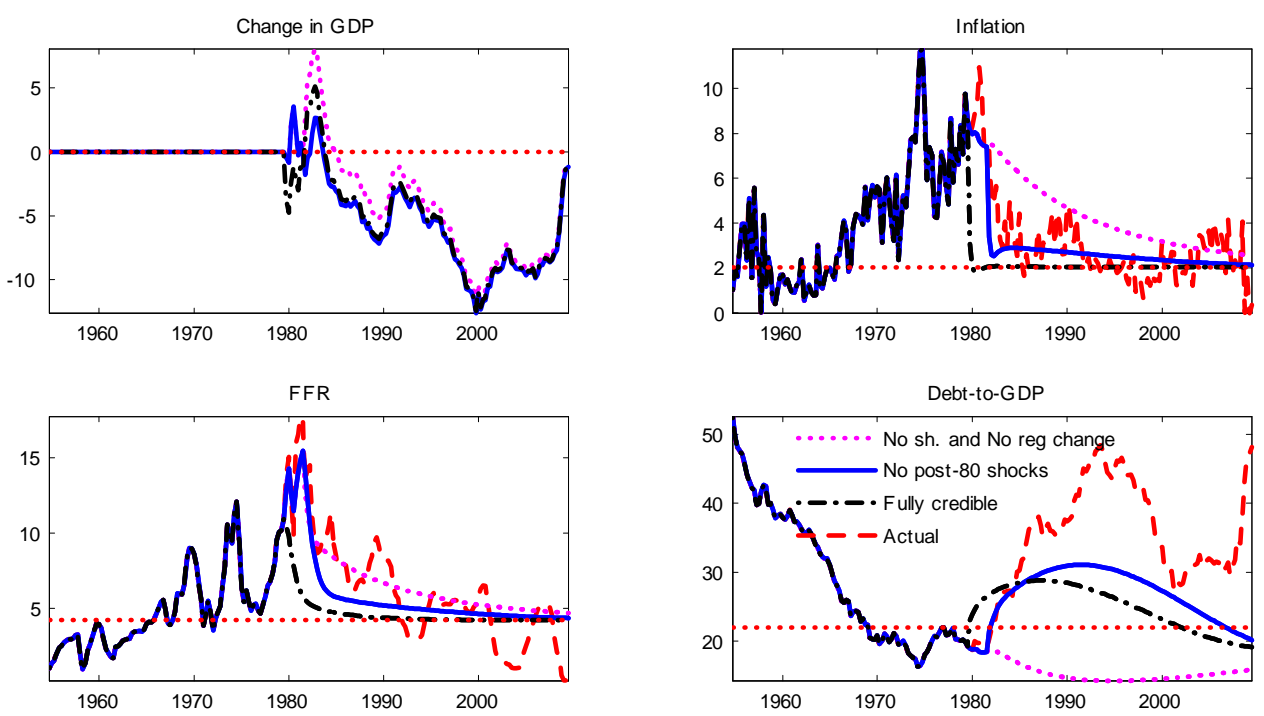

Figure 8: Revisiting the Volcker disinflation. We set all the shocks starting from the last quarter of 1979 to zero and we construct three counterfactual simulations. The first assumes that at the end of 1981, after the transitory period of $\mathrm{AM} / \mathrm{AF}$, policymakers reverted to the $\mathrm{PM} / \mathrm{AF}$ (dotted magenta line), the second keeps the estimated regime sequence unchanged (solid blue line), the last one assumes that in the last quarter of 1979 policymakers moved to the counterfactual Fully credible AM/PF regime.

would have been substantially larger with respect to the actual data and also with respect to the first counterfactual simulation. This should not be surprising, given that the tax rule in place still implies no response to the level of debt and inflation does not help in eliminating the fiscal burden.

Summarizing, these counterfactual simulations suggest that policymakers' behavior and agents' beliefs about future policymakers' behavior played a key role in the rise of trend inflation and the decline in the debt-to-GDP ratio observed during the '70s. If in the '70s agents had been confident about the regime change that was going to occur a few years ahead or policymakers had followed the $\mathrm{AM} / \mathrm{PF}$ regime, the Great Inflation would not have occurred. Furthermore, the debt-to-GDP ratio would have been larger during the '70s, implying that the low debt and the high inflation of the '70s are the two sides of the same coin.

\subsection{Revisiting the Volcker disinflation}

In this last counterfactual simulation we ask what would have happened if the regime changes of the early ' 80 s had not occurred. This simulation allows us to investigate the role of the switch to the $\mathrm{AM} / \mathrm{PF}$ that occurred at the end of 1981 and the importance of the transitory period that preluded such an event during which both monetary and fiscal policies were active. In order to isolate the effects of regime changes, we set all the shocks starting from the last quarter of 1979 to zero and we construct three counterfactual simulations: The first assumes that at the end of 1981, after the transitory period of $\mathrm{AM} / \mathrm{AF}$, policymakers reverted to the $\mathrm{PM} / \mathrm{AF}$ regime instead of moving to the $\mathrm{AM} / \mathrm{PF}$ regime (dotted magenta line), the second keeps the regime sequence unchanged (solid blue line), the last one assumes that in the last quarter of 1979 policymakers immediately moved to the 
$\mathrm{AM} / \mathrm{PF}$ policy mix and managed to convince agents that they will never abandon it (black dashed line). This corresponds to the Fully credible $A M / P F$ regime. Figure 8 presents the counterfactual and actual series. In interpreting these results, the reader might find useful to refer to the impulse responses presented in Subsection 3.2.3.

Several important facts stand out. First, even if monetary policy is already active as a result of the appointment of Volcker in August 1979, inflation does not drop immediately. This is because agents expect to revert back to the $\mathrm{PM} / \mathrm{AF}$ with high probability. It is only when fiscal policy accommodates the change in monetary policy that inflation experiences the large drop observed in the data. Without the switch to the AM/PF regime at the end of 1981, inflation would have been above target for a long time, even if all the shocks have been set to zero. Second, even if following the switch to the $\mathrm{AM} / \mathrm{PF}$ regime inflation experiences a large drop, it does not go to the steady state as it would if the regime change were perceived as once and for all. This is because the possibility of a return to the $\mathrm{PM} / \mathrm{AF}$ regime combined with the still large fiscal burden inherited from the past determines inflationary pressure. Third, if the regime change had not occurred, the economy would not have experienced the recession associated with the Volcker disinflation, as the positive change in output shows. This is not the case when the regime change is maintained. Finally, when the regime change is kept, the model is able to match the turnaround in the path of the debt-to-GDP ratio that suddenly starts increasing, moves above the steady state, and then approaches it from above. On the contrary, when the regime change is removed, the variable shows an extremely smooth behavior and approaches the steady state from below.

Overall, these results show that the regime change, and not the shocks, accounts for three important stylized facts observed during the early '80s: The sudden drop in inflation, the large recession associated with the Volcker disinflation, and the sudden change in debt dynamics. The results also explain why inflation did not drop as soon as Volcker attempted to bring it down at the end of 1979 and why it did not immediately stabilize on the target/steady state level once fiscal policy accommodated the change in monetary policy.

\subsection{Discussion}

The impulse responses presented in Subsection 3.2 are helpful to interpret the counterfactual simulations shown above. First, they illustrate that the rise in trend inflation can be explained by a lack of fiscal discipline that made a series of fiscal shocks inflationary and undermined the ability of the monetary authority to control inflation. In fact, the joint behavior of inflation and debt in response to a long term expenditure shock under the PM/AF regime is in line with what was observed over the first half of the sample, with a persistent increase in inflation and a slow-moving decline in the debtto-GDP ratio. Second, they illustrate why the increase in trend inflation practically disappears when the $\mathrm{AM} / \mathrm{PF}$ regime is imposed over the entire sample or agents are confident about the possibility of moving to such a regime: In both cases, the fiscal shocks that are inflationary under the PM/AF regime, are completely neutralized and the Federal Reserve regains its ability to control inflation. 
In the first case, this occurs because agents are not concerned about the possibility of returning to the $\mathrm{PM} / \mathrm{AF}$ regime, while in the confidence counterfactual the result is exclusively driven by the expectation mechanism: Agents are confident that at some point in the future the policy mix will change and this is enough to neutralize the effects of current policymakers' behavior. Finally, not all shocks that affect inflation can be completely stabilized. For example, in the short run the impact of a mark-up shock on inflation is substantially unaffected by the regime change. This explains why the counterfactual simulations determine a drastic change in the behavior of inflation at low frequencies, while they have little impact on its movements at medium and high frequencies.

The impulse responses of Subsection 3.2.3 are useful to understand why the attempts to disinflate of the '70s were unsuccessful and why the Volcker disinflation was still quite painful. If the monetary authority tries to disinflate without the necessary support of the fiscal authority, the result is a negligible decline in inflation associated with a sizeable contraction in output. In the moment that the attempt is aborted, inflation returns to a value that is larger than what it would have been if the monetary policy had never changed behavior. This "stepping on a rake" effect represents a key ingredient in linking our results to the work of Primiceri (2006), Cogley and Sargent (2005), and Sargent, Williams, and Zha (2006). In these papers the rise and fall of inflation result from the evolution of the central banks' beliefs about the structure of the economy. A central insight of these papers is that the Federal Reserve might have been reluctant to bring inflation down in the '70s because of the perceived trade-off between inflation and output growth. Our results suggest that this trade-off was in fact there and was due to a lack of coordination between the monetary and fiscal authorities. The moment the central bank tries to take the initiative and reduce inflation without coordinating with the fiscal authority, the result is a recession and a further increase in inflation.

Bianchi (2013b) and Fernandez-Villaverde, Guerron-Quintana, and Rubio-Ramirez (2010) have conducted counterfactual simulations in micro-founded models focusing on the consequences of changes in monetary policy only, assuming that a passive fiscal policy is always in place. A common finding is that replacing Burns with Volcker would have implied only a minor reduction of inflation in the '70s. In a similar way, removing the appointment of Volcker in August '79 would have only slightly delayed the return of inflation to the steady state. This is because different monetary policy regimes only affect how the burden of adverse shocks is redistributed between output and inflation. Instead, when a change in the entire policy mix is considered a series of fiscal shocks that are inflationary under the $\mathrm{PM} / \mathrm{AF}$ regime are completely neutralized if the $\mathrm{AM} / \mathrm{PF}$ regime is the only possible one or if it occurs very frequently.

Given the central role played by fiscal shocks, it is important to document that the model does not imply an unrealistic behavior for the long term component of government expenditure. The top panel of Figure 9 reports the model implied long term component of expenditure, ${ }^{9}$ showing that in fact the variable increases steadily in the '70s, but also that its behavior is remarkably smooth and arguably similar to what would be obtained by pre-filtering the data. The second panel reports the

\footnotetext{
${ }^{9}$ The series is obtained by filtering the data at the posterior mode and then applying the Kalman smoother.
} 

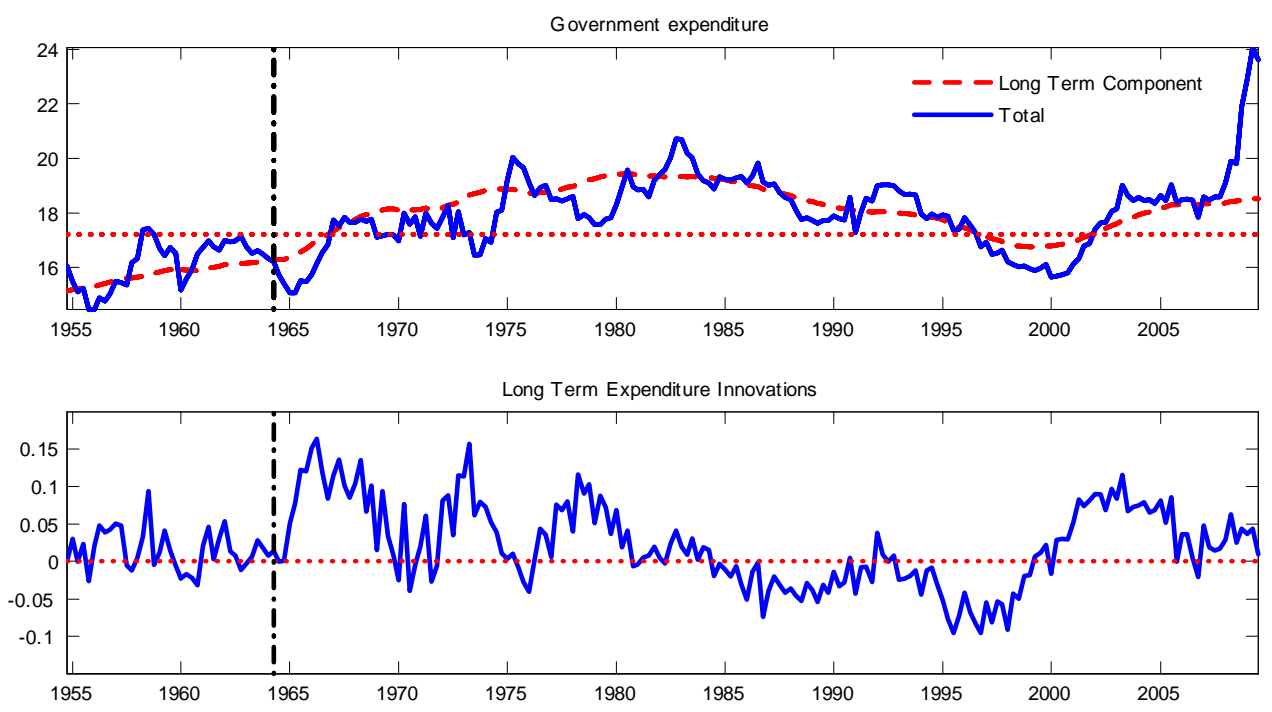

Figure 9: The top panel contains total government expenditure as a fraction of GDP and its filtered long term component. The horizontal line represents the steady state value. The lower panel reports the innovations to the long term component. The vertical bar marks President Johnson's first ever public reference to the 'Great Society' (May $7,1964)$.

long term component innovations. It is worth emphasizing that the most notable acceleration in the long term component occurs after the President Johnson's first ever public reference to the 'Great Society' that took place during a speech on May 7, 1964 at Ohio University (marked by the vertical bar).

Therefore, the model provides support for the argument proposed by Bernanke (2003) that the early manifestation of the Great Inflation can be tracked back to the Great Society initiatives. At the same time, it is important to keep in mind that these shocks are inflationary only when agents expect the $\mathrm{PM} / \mathrm{AF}$ regime to prevail for a long time. If the $\mathrm{AM} / \mathrm{PF}$ regime had been in place, the increase in inflation would not have occurred. Given the nature of these programs, the American public might not have found it fully credible that future administrations would have taken the necessary steps to cover the higher level of expenditure.

\section{$5 \quad$ Inflation Expectations, Persistence, and Volatility}

We will now show that the changes in the monetary/fiscal policy mix identified in this paper can account for the evolution of inflation expectations and the decline in the persistence and volatility of inflation that has been documented by Stock and Watson (2007).

\subsection{Inflation expectations and persistence}

The solid-circled blue line in the first panel of Figure 10 reports the model implied one-year-ahead inflation expectations. These are computed taking into account the possibility of regime changes using the methods outlined in Bianchi (2013a). The series tracks remarkably well the evolution 

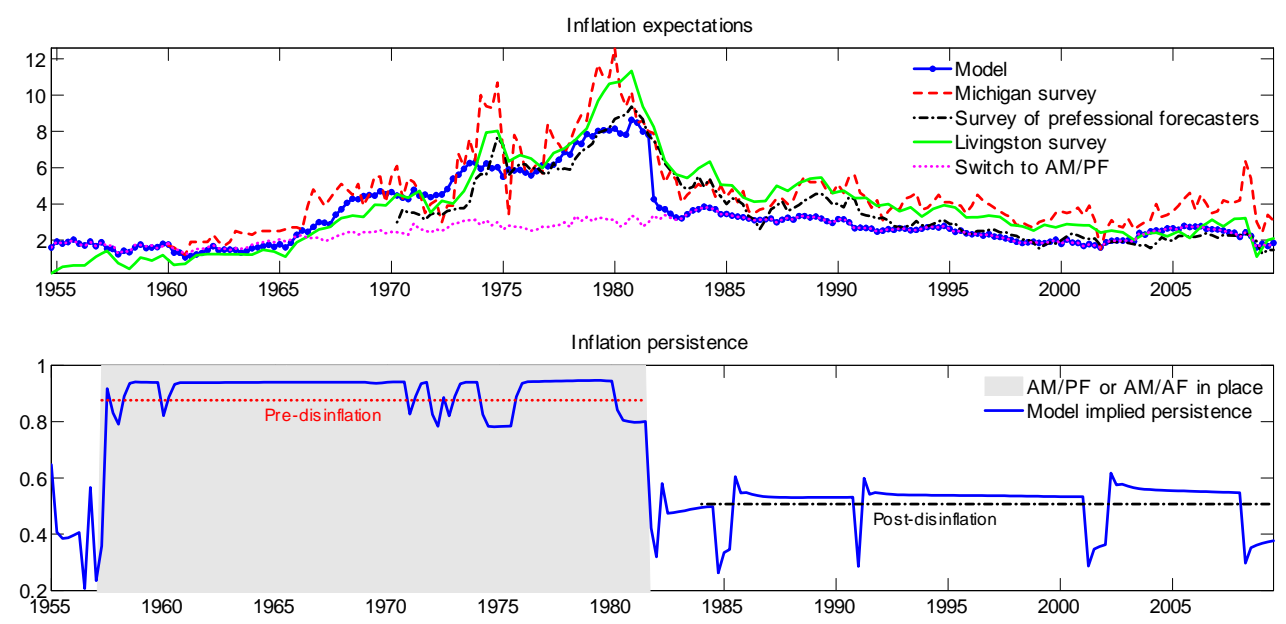

Figure 10: The top panel reports five measures of one-year-ahead inflation expectations: (1) Model implied inflation expectations; (2) The mean of the Michigan survey; (3) the Survey of professional forecasters; (4) the semi-annual Livingston survey; (5) counterfactual inflation expectations obtained assuming a switch to the AM/PF regime. The lower panel plots the model implied inflation persistence. The two horizontal lines report the persistence of inflation before and after the disinflation of the early-80s.

of three popular measures of inflation expectations: The Survey of Professional Forecasters (black dotted-dashed line), the Michigan survey (red dashed line), and the Livingston survey (solid green line). Inflation expectations are well anchored at the beginning of the sample, while starting from the mid-60s they experience a smooth and persistent increase. As in the data, inflation expectations do not move in response to the disinflationary attempts of the late '60s and mid-70s and to the appointment of Volcker. Only when the change in the whole policy mix occurs at the end of 1981, inflation expectations drop. We then observe a slight downward trend that lasts until the early 2000s. In the data, the drop in inflation expectations that followed the disinflation of the early-80s is more gradual than in the model. Bianchi and Melosi $(2012,2013)$ consider models in which agents have to learn the likely duration of a change in policymakers' behavior. In that class of models, it would take time for agents to become convinced that the switch to the AM/PF regime is going to last for a long time. Therefore, the smooth decline in inflation expectations would reflect concerns about the possibility of a return to the policies of the '70s that become less and less relevant as more time is spent under the $\mathrm{AM} / \mathrm{PF}$ regime. Estimating a version of this model with such a learning mechanism is certainly interesting, but also computationally challenging. We regard this as material for future research.

To highlight the role played by changes in the monetary/fiscal policy mix, we also report what inflation expectations would have been if the $\mathrm{AM} / \mathrm{PF}$ regime had been in place (dotted magenta line). Notice that we keep the current state of the economy unchanged implying that only expectations are counterfactual. In this case, the model would completely miss the run-up of inflation expectations. This is because rational agents, observing the $\mathrm{AM} / \mathrm{PF}$ regime in place today, would expect a quick disinflation, no matter how high inflation is.

To understand why changes in the policy mix help in matching the behavior of inflation expectations, the second panel of Figure 10 reports the historical evolution of inflation persistence as implied 
by the model. The gray area denotes periods during which fiscal policy is active. Two patterns stand out. First, moving from the low volatility to the high volatility regime determines only a small drop in inflation persistence when fiscal policy is active. Second, the most drastic change in inflation persistence is determined by the switch to the $\mathrm{AM} / \mathrm{PF}$ regime at the end of 1981 . The model implied inflation persistence moves from around .94 to around .55. These values are very close to the values of inflation persistence as observed in the data (see horizontal lines in the graph), implying that the model can account for the break in inflation persistence documented in the literature. This, in turn, helps in explaining why inflation expectations move so closely with actual inflation before the disinflation of the early ' 80 s, but not after.

The fact that the model can account for the path of inflation expectations is important when considering alternative theories of the rise of inflation. Among the most fascinating is certainly the one proposed by Orphanides (2002) that argues that policymakers in the 1970s overestimated potential output leading to overexpansionary policies, which ultimately resulted in high inflation. After noticing that our model predicts a positive output gap in the '70s, implying that the two explanations are not mutually exclusive, it is worth pointing out that the path of inflation expectations seems to play in favor of the story proposed in this paper. First, inflation and inflation expectations started moving in the mid-'60s and kept increasing steadily until the early '80s. This pattern seems to require that not only policymakers were wrong, but they were increasingly wrong. Furthermore, as pointed out by Levin and Taylor (2012), the timing is not entirely consistent with the evolution of policymakers' beliefs suggested by Orphanides (2002), who argues that policymakers' beliefs were especially far from the truth in the '70s. Instead, in the data inflation expectations started moving before that. Second, under the assumption that policymakers' beliefs about the economy are wrong, while their goals are unchanged, agents should have expected a fairly quick return to steady state inflation, unless we are willing to assume that the public had a clear understanding of the learning process faced by the Fed and a sort of pessimism about its ability to get to the truth. Finally, inflation expectations did not seem to react at all to the disinflationary attempts of the '60s and '70s and to the appointment of Volcker, while they started moving around 1981.

Our model rationalizes all of these aspects. First, inflation and inflation expectations started moving in correspondence to large fiscal disturbances. Second, inflation is expected to quickly return to the target only if a switch to the AM/PF occurs. Otherwise, inflation and inflation expectations move very closely due to the high inflation persistence that arises in the moment that the fiscal authority is perceived as the dominant authority. Finally, inflation expectations do not respond to a disinflationary attempt of the monetary authority unless this is backed by the fiscal authority.

The ability of the model to replicate the behavior of inflation expectations also implies that it is able to track the path of the real interest rate. Figure 11 compares the actual path of the ex-ante one-year real interest rate, computed taking the difference between the FFR and the oneyear-ahead Livingston inflation expectations, with its model implied counterpart (solid blue line) and the counterfactual series in which the current state of the economy is kept unchanged, but 


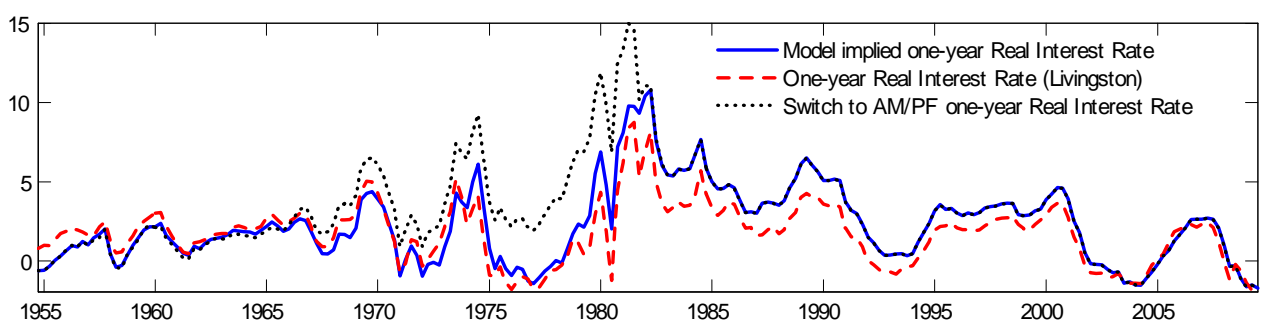

Figure 11: The figure reports three measures of the one-year Real Interest Rate: (1) model implied, computed as the difference between the FFR and one-year-ahead inflation expectations; (2) in the data, obtained taking the difference between the FFR and the Livingston survey; (3) counterfactual that assumes a switch to the AM/PF regime.

policymakers behave according to the $\mathrm{AM} / \mathrm{PF}$ regime (red dotted line). The model is clearly able to account for the prolonged period of low and negative interest rates that characterized the '70s. On the other hand, under the counterfactual series, the real interest rate would have been substantially larger. Notice that, except for the two disinflationary attempts of the late '60s and '73/'74, ex-ante real interest rates were extremely low during a period in which inflation was constantly trending up. This was true even toward the end of the '70s, when inflation was getting out of control. Levin and Taylor (2012) suggest that this pattern is problematic for those papers that aim at explaining inflation through a misperception of the sacrifice ratio because a policy maker that is concerned about the cost of disinflation would be very adverse to allow for a further increase of inflation at the end of the '70s. In our model, the very low real interest rate can instead be rationalized in light of the dominant role played by the fiscal authority. Finally, the model captures the reversal in the real interest rate in the early ' 80 s as a result of a switch to the AM/PF regime.

The ability to generate a break of inflation persistence is also important when relating our results to the work of Primiceri (2006) who explains the rise of inflation with a model in which policymakers are uncertain about the true structure of the economy. A key ingredient to obtain the rise of inflation consists in assuming a unit root in the Phillips curve that is ignored by policymakers in the 1960s. Primiceri (2006) argues that such an assumption is in line with the available data prior to 1960. For example, Barsky (1987) shows that strong inflation persistence emerged only around 1960. Our results provide an explanation for the rise of inflation persistence based on the interaction between the monetary and fiscal authorities, instead of assuming breaks in the Phillips curve. Specifically, once fiscal policy is perceived as the dominant authority, inflation persistence remains high independent of the conduct of monetary policy and the central bank loses its ability to stabilize inflation.

\subsection{Macroeconomic volatility}

We now turn to analyze the implications of changes in policymakers' behavior for inflation and output volatilities. Figure 12 reports standard deviations and variance decompositions at different horizons varying the initial policy mix. The low volatility regime is assumed to be in place at time zero. ${ }^{10}$ Both the standard deviations and variance decompositions are computed taking into account the

\footnotetext{
${ }^{10} \mathrm{~A}$ similar graph that assumes the high volatility regime in place at time zero is presented in Appendix D.
} 

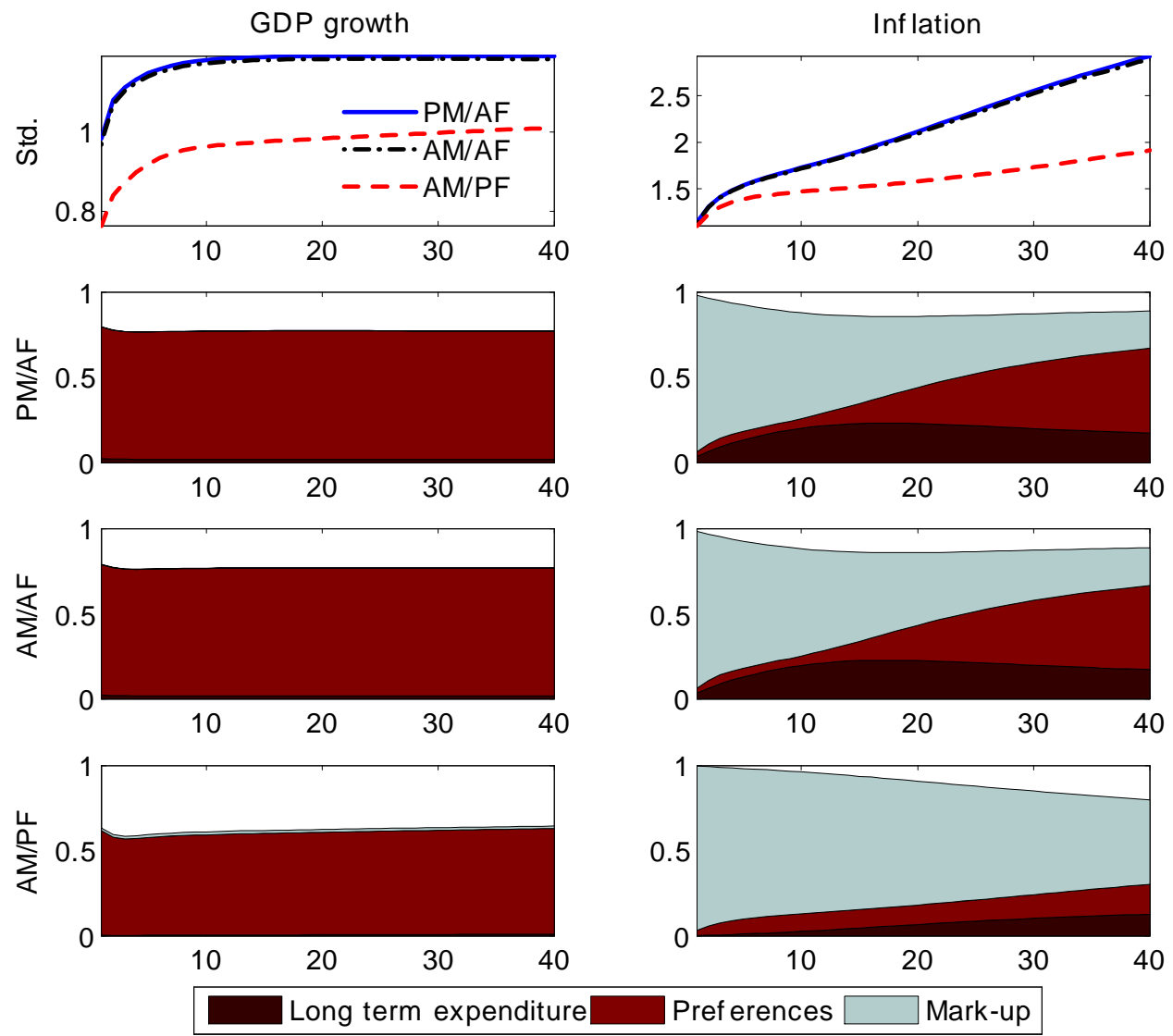

Figure 12: The first row reports the model implied standard deviations at different horizons for output growth and inflation across different initial policy combinations. The low volatility regime is assumed to be in place at time zero. Both the standard deviations and variance decompositions take into account the possibility of regime changes.

possibility of regime changes using the methods described in Bianchi (2013a). Regarding inflation volatility, we observe a substantial reduction moving from the $\mathrm{PM} / \mathrm{AF}$ to the $\mathrm{AM} / \mathrm{PF}$ regime. When the economy is currently under the $\mathrm{AM} / \mathrm{AF}$ regime, the evolution of inflation volatility mimics the pattern observed for the $\mathrm{PM} / \mathrm{AF}$ regime. This is consistent with the fact that from the $\mathrm{AM} / \mathrm{AF}$ regime there is a very high probability of moving to the $\mathrm{PM} / \mathrm{AF}$ regime. A similar argument holds for output volatility. At all horizons, the expected volatility is lower if the economy is currently in the AM/PF regime. Of course, as the horizon goes to infinity, the volatilities would converge to their ergodic values. However, given that the regimes are quite persistent, being in or out of the $\mathrm{AM} / \mathrm{PF}$ regime has a large impact on macroeconomic volatility.

Preference shocks get the lion's share when it comes to understanding the sources of output growth volatility. As for inflation volatility, preference and long term expenditure shocks play a very important role when out of the AM/PF regime. At the ten years horizon, more than $60 \%$ of inflation variability is explained by these two shocks. When the $\mathrm{AM} / \mathrm{PF}$ regime is in place, the contribution of the long term component is initially small, but it keeps growing as the horizon increases. This is for two reasons. First, even under the AM/PF regime, shocks to the long term component of expenditure have an effect on the macroeconomy. Second, as the horizon increases, so does the probability that a shift to the $\mathrm{PM} / \mathrm{AF}$ actually occurred. 
Summarizing, over the long horizon fiscal imbalances play an important role in explaining movements in inflation when there is a lack of commitment to stabilize debt. Even under the AM/PF regime, we find that this mechanism is important because agents take into account the possibility of moving to the PM/AF regime. This result is in line with the evidence presented in De Graeve and Queijo von Heideken (2013) and Kliem, Kriwoluzky, and Sarferaz (2013) that document low frequency comovements between inflation and fiscal deficits.

\section{Historical Accounts}

We find it instructive to reconcile the results of the paper to historical accounts of the interaction between the fiscal and monetary authorities. Although in the early years of our sample, William Martin (Chair of the Board of Governors April 1951- January 1970), is successful in keeping inflation low, the first spur of inflation occurred under his chairmanship, in the second half of the '60s. As documented by Meltzer (2009), Martin regarded himself as a public servant (see also Taylor, 2011) and, in his own words, thought that the central bank had to be "independent within the government." Meltzer argues that this view led the Federal Reserve to accept "its role as a junior partner by agreeing to coordinate its actions with the administration's fiscal policy."

Arthur Burns' appointment (Chair of the Board of Governors February 1970 - February 1978) meant a turn toward an even more expansionary monetary policy. There is now common agreement that throughout his chairmanship, Burns often had to succumb to the requests of the US administration. During a conversation occurring on October 23, 1969, just after Burns's nomination to the Fed had been announced, Richard Nixon invited Burns "to see [him] privately anytime" and suggested to communicate through an intermediary in order to preserve "the myth of the autonomous Fed" (Abrams, 2006). Levin and Taylor (2012) argue that these political pressures are crucial in understanding the rise in inflation and report that Burns (1979) himself acknowledged this: "...the central banks' practical capacity for curbing an inflation that is driven by political forces is very limited."

With inflation trending up at a quick pace in the 1970s, there are two failed disinflationary attempts, one early in 1969-1970 and the second in 1973. Both share similar features. On the one hand, the interest rate increases but inflation does not fall. On the other hand, as documented for example by Weise (2012) using FOMC minutes and transcripts, it was widely recognized that these disinflationary attempts were hindered by political pressures from the administration at that time who wanted much more gradual approaches to price stability. As an effect, Weise (2012) documents

how in both cases, the more contractionary strategy was then abandoned as politically unfeasible and a much more middle ground policy was adopted.

As shown in Figure 2, our model interprets these failed attempts as a likely outcome of a regime in which both monetary and fiscal authorities are active. Consistent with the historical accounts, in this regime the Fed attempts a contractionary policy but the fiscal policy is not changing its fiscal stance to surrender control over inflation determination, resulting in potentially even higher inflation. 
Although qualitatively similar, according to our estimates, the 1973 disinflation attempt was even less decisive than that of 1969, when the smoothed probability of the AM/AF regime was significantly larger. This different intensity is consistent with the view described in Weise (2012) who argues that the Fed had a greater willingness in 1969 to end inflation than it would have at any time during the 1970s.

Jimmy Carter's victory in the 1976 presidential election, a campaign during which he had criticized the Fed for not following a stronger expansionary monetary policy, sets up an even weaker political support for fighting inflation. This lead Arthur Burns and William Miller (Chair of the Board of Governors March 1978 - August 1979), as documented by Weise (2012) and Wells (1994), to express dread at the thought that the Fed would be forced to take on inflation by itself. Instead, they looked to the Administration to take the lead in controlling inflation. ${ }^{11}$

By the late 1970s the general public became increasingly frustrated and worried about the high cost of inflation. Meltzer (2009) notes that in Gallup polls from 1978 to 1982, more than 50 percent of respondents listed inflation and the high cost of living as the most important problems facing the country. In August 1979 Paul Volcker is appointed chairman, viewed at the time as a signal that the Fed is expected to take action. However, Volcker's appointment and initial increase in the FFR in October 1979 did not result in a sudden disinflation. Goodfriend and King (2005) argue that "the start of a deliberate disinflation dates to late 1980" and that this initial increase in the FFR did not represent a substantial departure from the way monetary policy was conducted in the '70s: A timid attempt at controlling inflation, resulting in even higher inflation. The results reported in Figure 5 provide an explanation for why this first attempt was not successful. If the central bank tries to gain control of inflation without the support of the fiscal authority the result is even higher inflation.

This first attempt suffered a further important delay when the Fed accommodated the request of the Carter administration to introduce credit controls on March 14, 1980. This choice proved to be disastrous for two reasons. First, it determined a decline in the FFR and did not prevent inflation from rising, an effect interpreted by our estimation as a likely return to the PM/AF regime. Second, it undermined once again the independence of the monetary authority. The result was that the Federal Reserve had to start the effort all over again. The credit controls were removed in July 1980 and this time Volcker kept interest rates high for a prolonged period of time with no interference by the Reagan administration.

Samuelson (2008) documents how within this period, the political support was markedly different between the Carter and Reagan administration. The former was widely viewed as unable to help control inflation. ${ }^{12}$ In fact, Carter himself later judged that inflation had been the decisive issue against him in losing the presidential election to Reagan. On the opposite side, running on an antiinflation platform, Reagan brought a strong-willed approach to fighting inflation. "Unlike some of

\footnotetext{
${ }^{11}$ For example, in March 1978 Miller worried that "time is very short for them [the administration] to take some more believable steps in fighting inflation and if it's not done, inflation is going to be left to the Federal Reserve and that's going to be bad news" (Weise (2012))

${ }^{12}$ For example, in early 1980 Carter was asked at a press conference what he planned to do about inflation. He replied, "It would be misleading for me to tell any of you that there is a solution to it."
} 
his predecessors, [Reagan] had a strong visceral aversion to inflation," Volcker later said. Although the strong contractionary policy and associated economic slump lead to significant social pressure for a policy reversal, such that his popularity rating fell from 68 percent in 1981 to 45 percent in 1982, Reagan did not retreat. Samuelson (2008) recalls that differently from the previous disinflation attempts, he refused to criticize the Fed chairman publicly, to urge a lowering of interest rates, or to work behind the scenes to bring that about. ${ }^{13}$ Backed by this strong political support, the monetary authority pushed forward the aggressive contractionary monetary policy. ${ }^{14}$ Volcker kept interest rates high enough until inflation finally fell substantially in 1982.

Consistent with these accounts, our estimation views the period starting from Volcker's appointment until the beginning of 1982 as reflecting high uncertainty about which authority will give up the control of inflation. In our interpretation of the events of the early '80s, Reagan played a pivotal role in determining the drop of inflation, providing the necessary support for the Federal Reserve's initiatives. The Great inflation is finally conquered when the private sector is convinced that the monetary authority has the fiscal backing to control inflation.

It is also useful to note that the support for this fiscal backing did not have to result in immediate fiscal adjustments. In Figure 13 we illustrate this point by comparing the actual behavior of the primary surplus during the ' 80 s with what is implied by the model using the counterfactual simulations of Subsection 4.2. When the regime switch to the AM/PF regime is maintained (solid blue line), we observe the sudden and pronounced drop in the primary surplus, followed by a persistent and slow moving increase, as found in the data. Under the counterfactual scenario of a return to the $\mathrm{PM} / \mathrm{AF}$ regime we would have instead observed a sequence of primary surpluses (magenta dotted line). Finally, an immediate and fully credible switch to the AM/PF regime would have also induced a primary deficit in the short run, but this would have been less pronounced.

The impulse responses reported in Figure 5 and the counterfactual simulation of Subsection 4.2 highlight why our model predicts that at that time the tax-to-GDP ratio should go down and the debt-to-GDP ratio should go $u p$, in line with what is observed in the data. The reasons are two-fold. First, when the switch to the AM/PF regime occurs in the early 1980s, the debt-to-GDP ratio is at a historical minimum, given that twenty years of $\mathrm{PM} / \mathrm{AF}$ policy have already erased a significant portion of the fiscal burden. Second, the economy entered a recession as a result of the deflationary effort. The fiscal backing only requires that over the long horizon tax revenues, instead of inflation,

\footnotetext{
${ }^{13}$ When the president did speak, he supported Volcker. At a press conference on February 18, 1982, Reagan called inflation "our number one enemy" and referred to fears that "the Federal Reserve Board will revert to the inflationary monetary policies of the past." The president pledged that this wouldn't happen. "I have met with Chairman Volcker several times during the past year," he said. "We met again earlier this week. I have confidence in the announced policies of the Federal Reserve."

${ }^{14}$ At the July 1981 meeting Kansas City Fed President Roger Guffey argued: "Historically, the Federal Reserve has always come up to the hitching post and then backed off simply because the Administration and the Congress have thrown bricks at us or have not been supportive of a policy of restraint. Through the course of recent history at least, we've backed off and we've made a mistake each time. I think we have an opportunity this time to carry forward what we should have done before because for the first time ever we do have, for whatever length of time, the support of the Administration at least. So, we ought to take advantage of that opportunity."(FOMC meeting Transcripts, July 81, cf. Weise (2012)).
} 


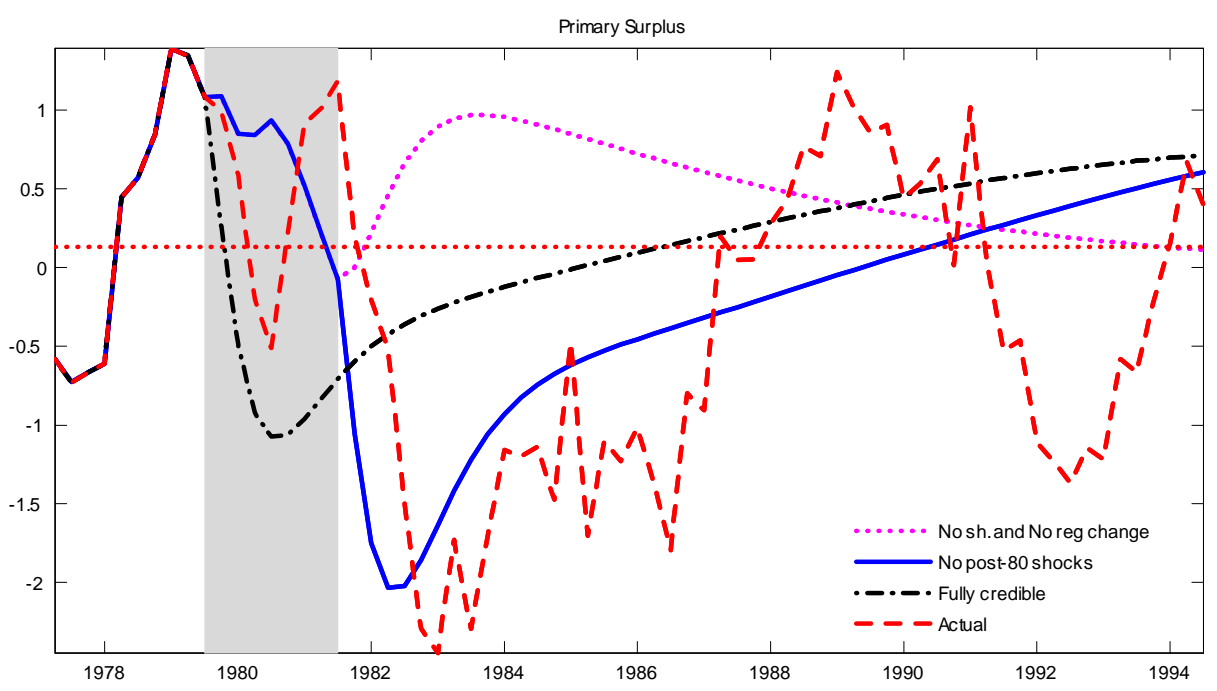

Figure 13: The figure compares the actual behavior of the primary surplus during the ' $80 \mathrm{~s}$ with that is implied by the model. We set all the shocks starting from the last quarter of 1979 to zero and we construct three counterfactual simulations. The first assumes that at the end of 1981, after the transitory period of AM/AF, policymakers reverted to the PM/AF (dotted magenta line), the second keeps the estimated regime sequence unchanged (solid blue line), the last one assumes that in the last quarter of 1979 policymakers moved to the counterfactual Fully credible AM/PF regime.

are expected to go up in order to repay the fiscal burden. In the meantime the debt-to-GDP ratio continues increasing for a while, as seen in the data, due to the higher real interest rates, the recession, and the sluggish adjustment of taxes. In other words, what matters for the dynamics of inflation and debt is not what occurs to tax revenues at that time of the switch, but how agents expect the fiscal burden to be financed.

While our model can account for the observed initial fall in the tax-to-GDP ratio and the increase in the debt-to-GDP ratio at the time of the regime switch, it is further useful to evaluate historically the extent to which such a switch towards a passive fiscal policy is consistent with the Reagan tax reform. The first step in this reform was the Economic Recovery Tax Act enacted in August 1981. While this tax cut led to an immediate fiscal deficit, it was very soon followed by partially compensating deficit reducing measures that were aimed at increasing tax revenues, either through higher tax rates or through expanding the tax base. These changes included the Tax Equity and Fiscal Responsibility Act of 1982, the Social Security Amendments of 1983, and the Deficit Reduction Act of 1984 .

The tax reform also signalled a series of further efforts aimed toward reducing government spending and increasing future tax revenues through a larger tax base. On the spending side, Romer and Romer (2009) provide ample historical accounts on how Reagan was a strong advocate of spending reductions and that he viewed the tax cuts as the most effective way to shrink the size of the government, following the "starve-the-beast" hypothesis. For example, as documented by Romer and Romer (2009), in a February 1981 speech presenting his economic program, Reagan identified "reducing the growth in government spending and taxing" as a central goal, while simultaneously advocating for a reallocation of spending toward "those functions which are the proper province of government," such 
as national defense. Thus, even if the very early fiscal reform led to higher initial fiscal deficit, the historical context suggests that in the early 1980s, consistent with our estimated regime switch, there was a fundamental shift from the 1970s in the administration's approach towards fiscal sustainability. As detailed in these historical accounts, Reagan was strongly in favor of a small government, and, more importantly, not willing to allow inflation to be used as a tool for fiscal adjustment.

Our results are further in line with Cochrane (1998) who argues that the fall of inflation of the early ' 80 s can be rationalized by a revision in expected future surpluses induced by the Reagan tax reforms. Lower rates and a broader tax base mean better growth and eventually better tax revenues. In our case, the change in expectations is induced by a switch in the monetary/fiscal policy mix. Agents understand that once monetary policy stops accommodating the behavior of the fiscal authority and the fiscal authority publicly endorses such a decision, the government will have to move surpluses in order to stabilize debt.

\section{Conclusions}

This paper has shown that the rise and fall of US inflation can be explained by a change in the balance of power between the monetary and fiscal authorities. When the fiscal authority is the leading authority, fiscal imbalances generate long lasting and persistent increases in inflation and the monetary authority loses its ability to control inflation. The effects of these shocks last as long as agents expect the fiscal authority to prevail in the future. Therefore, if the monetary authority tries to disinflate without the backing of the fiscal authority inflation barely moves. However, the moment that the fiscal authority accommodates the central bank's behavior inflation quickly drops, the economy enters a recession, and the debt-to-GDP ratio starts increasing. These features characterized the events of the early ' 80 s and can therefore be rationalized by the change in the policy mix itself.

Using counterfactual simulations we then established three important results. First, to the extent that the Great Inflation was caused by the way fiscal and monetary shocks propagate under the $\mathrm{PM} / \mathrm{AF}$ regime, if agents had been confident about the regime change of the early '80s or if the $\mathrm{AM} / \mathrm{PF}$ regime had been in place over the entire sample, the Great Inflation would not have occurred. Second, given that the fall in inflation in the early ' 80 s is explained by a regime change and not by exogenous shocks, if the switch to the AM/PF regime had not occurred inflation would have remained above the steady state for another fifteen years. Third, the Volcker disinflation would have been less painful if agents had perceived the switch to the AM/PF as fully credible. 


\section{References}

Abrams, B. A. (2006): "How Richard Nixon Pressured Arthur Burns: Evidence from the Nixon Tapes," Journal of Economic Perspectives, 20(4), 177-188.

Atkeson, A., V. Chari, and P. Kehoe (2009): "Sophisticated Monetary Policies," Quarterly Journal of Economics, 125(1), 47-89.

Baele, L., G. Bekaert, S. Cho, K. Inghelbrecht, and A. Moreno (2011): "Macroeconomic Regimes," Columbia University working paper.

BARSKY, R. B. (1987): "The Fisher hypothesis and the forecastability and persistence of inflation," Journal of Monetary Economics, 19(1), 3-24.

Bernanke, B. (2003): "Constrained Discretion and Monetary Policy," Remarks before Money Marketeers of New York University.

Bhattarai, S., J. Lee, and W. Park (2012): "Policy Regimes, Policy Shifts, and U.S. Business Cycles," working paper.

BiAnchi, F. (2012): "Evolving Monetary/Fiscal Policy Mix in the United States," American Economic Review, Papers and Proceedings, forthcoming.

(2013a): "Methods for Measuring Expectations and Uncertainty in Markov-switching Models," CEPR discussion paper 9705.

(2013b): "Regime Switches, Agents' Beliefs, and Post-World War II U.S. Macroeconomic Dynamics," Review of Economic Studies, 80(2), 463-490.

Bianchi, F., And L. Melosi (2012): "Constrained Discretion and Central Bank Transparency," working paper.

(2013): "Dormant Shocks and Fiscal Virtue," 2013 NBER Macroeconomics Annual, forthcoming.

Burns, A. F. (1979): "The Anguish of Central Banking," Per Jacobsson Lecture, Sava Centar Complex, Belgrade, Yugoslavia.

Chib, S. (1996): "Calculating Posterior Distributions and Model Estimates in Markov Mixture Models," Journal of Econometrics, 75, 79-97.

Clarida, R., J. Gali, and M. Gertler (2000): "Monetary Policy Rules and Macroeconomic Stability: Evidence and Some Theory," Quarterly Journal of Economics, 115, 147-180.

Cochrane, J. H. (1998): "A Frictionless Model of U.S. Inflation," in NBER Macroeconomics Annual 1998, ed. by B. S. Bernanke, and J. J. Rotemberg, pp. 323-384. MIT Press, Cambridge, MA.

(2001): "Long Term Debt and Optimal Policy in the Fiscal Theory of Price Level," Econometrica, 69, 69-116.

- (2011): "Understanding Policy in the Great Recession: Some Unpleasant Fiscal Arithmetic," European Economic Review, 55, 2-30.

Cogley, T., G. Primiceri, and T. J. Sargent (2010): "Inflation-Gap Persistence in the U.S," AEJ Macroeconomics, 2(1), 43-69. 
Cogley, T., And T. J. Sargent (2005): "The Conquest of American Inflation: Learning and Robustness to Model Uncertainty," Review of Economic Dynamics, 8, 528-563.

Coibion, O., and Y. Gorodichenko (2011): "Monetary Policy, Trend Inflation, and the Great Moderation: An Alternative Interpretation," American Economic Review, 101(1), 341-370.

Davig, T., H. Chung, And E. M. Leeper (2007): "Monetary and Fiscal Policy Switching," Journal of Money, Credit, and Banking, 39(4), 607-635.

Davig, T., And T. Doh (2013): "Monetary Policy Regime Shifts and Inflation Persistence," The Review of Economics and Statistics, forthcoming.

Davig, T., And E. M. Leeper (2006): "Fluctuating Macro Policies and the Fiscal Theory," NBER Macroeconomics Annual 2006, pp. 247-298.

(2007): "Generalizing the Taylor Principle," American Economic Review, 97(3), 607-635.

De Graeve, F., and V. Queijo von Heideken (2013): "Identifying Fiscal Inflation," Sveriges Riksbank working paper.

Eusepi, S., And B. Preston (2012): "Fiscal Foundations of Inflation: Imperfect Knowledge," Working Paper.

Farmer, R. E., D. F. Waggoner, and T. Zha (2009): "Understanding Markov-Switching Rational Expectations Models," Journal of Economic Theory, 144, 1849-1867.

- (2011): "Minimal State Variable Solutions to Markov-Switching Rational Expectations Models," Journal of Economic Dynamics and Control, 35(12), 2150-2166.

Fernandez-Villaverde, J., P. Guerron-Quintana, and J. F. Rubio-Ramirez (2010): "Fortune or Virtue: Time-Variant Volatilities Versus Parameter Drifting in U.S. Data," NBER Working Papers 15928, National Bureau of Economic Research, Inc.

Goodfriend, M., And R. King (2005): "The Incredible Volcker Disinflation," Journal of Monetary Economics, 52(5), 981-1015.

Hall, G. J., and T. J. Sargent (2011): "Interest Rate Risk and Other Determinants of PostWWII U.S. Government Debt/GDP Dynamics," American Economic Journal: Macroeconomics, $3(3), 192-214$.

Hamilton, J. D. (1989): "A New Approach to the Economic Analysis of Nonstationary Time Series and the Business Cycle," Econometrica, 57, 357-384.

Iskrev, N. (2010a): "Evaluating the Strength of Identification in DSGE models. An a priori Approach," Working paper.

(2010b): "Local Identification in DSGE Models," Journal of Monetary Economics, 57(2), 189-202.

Justiniano, A., And G. Primiceri (2008): "The Time Varying Volatility of Macroeconomic Fluctuations," American Economic Review, 98(3), 604-41.

Kim, C.-J., And C. R. Nelson (1999): State-Space Models with Regime Switching. MIT Press, Cambridge, Massachusetts.

Kliem, M., A. Kriwoluzky, and S. Sarferaz (2013): "On the low-frequency relationship be- 
tween public deficits and inflation," working paper.

Leeper, E. M. (1991): "Equilibria Under Active and Passive Monetary and Fiscal Policies," Journal of Monetary Economics, 27, 129-147.

Leeper, E. M., M. Plante, and N. Traum (2010): "Dynamics of fiscal financing in the United States," Journal of Econometrics, 156(2), 304-321.

Levin, A., And J. Taylor (2012): "Falling Behind the Curve: A Positive Analysis of Stop-Start Monetary Policies and the Great Inflation," in The Great Inflation, Athanasios Orphanides and Michael Bordo (Eds.), University Chicago Press, forthcoming.

Liu, Z., D. Waggoner, and T. Zha (2011): "Sources of the Great Moderation: A RegimeSwitching DSGE Approach," Quantitative Economics, 2(2), 251-301.

Lubik, T., And F. Schorfheide (2004): "Testing for Indeterminacy: An Application to U.S. Monetary Policy," American Economic Review, 94(1), 190-217.

Martin, F. (2012): "Debt, Inflation and Central Bank Independence," working paper.

Meltzer, A. H. (2009): A History of the Federal Reserve. University of Chicago Press, Chicago.

Orphanides, A. (2002): "Monetary Policy Rules and the Great Inflation," American Economic Review, 92(2), 115-120, (Proceedings issue).

Primiceri, G. (2006): "Why Inflation Rose and Fell: Policymakers' Beliefs and US Postwar Stabilization Policy," The Quarterly Journal of Economics, 121(August), 867-901.

Romer, C., and D. H. Romer (2009): "Do Tax Cuts Starve the Beast? The Effect of Tax Changes on Government Spending," Brookings Papers on Economic Activity.

Samuelson, R. J. (2008): The Great Inflation and its Aftermath: The Past and Future of American Affluence. Random House Digital, Inc.

Sargent, T., and N. Wallace (1981): "Some Unpleasant Monetarist Arithmetic," Federal Reserve Bank of Minneapolis Quarterly Review, Fall, 1-17.

Sargent, T., N. Williams, and T. Zha (2006): "Shocks and Government Beliefs: The Rise and Fall of American Inflation," American Economic Review, 96(4), 1193-1224.

Schorfheide, F. (2005): "Learning and Monetary Policy Shifts," Review of Economic Dynamics, $8(2), 392-419$.

Sims, C. A. (1994): "A Simple Model for Study of the Determination of the Price Level and the Interaction of Monetary and Fiscal Policy," Economic Theory, 4, 381-399.

(2011): "Stepping on a Rake: The Role of Fiscal Policy in the Inflation of the 1970's," European Economic Review, 55(1), 48-56.

Sims, C. A., And T. Zha (2006): "Were There Regime Switches in US Monetary Policy?," American Economic Review, 91(1), 54-81.

Stock, J. H., and M. W. Watson (2007): "Why Has U.S. Inflation Become Harder to Forecast?," Journal of Money, Credit, and Banking, 39, 3-34.

Taylor, J. B. (2011): "Review of Allan H. Meltzer's A history of the Federal Reserve, VOlume 2, University of Chicago Press, 2009," Journal of Monetary Economics, 58, 183-189. 
Weise, C. L. (2012): "Political Pressures on Monetary Policy During the US Great Inflation," American Economic Journal: Macroeconomics, 4(2), 33-64.

Wells, W. (1994): Economist in an Uncertain World: Arthur F. Burns and the Federal Reserve, 1970-78. Columbia University Press.

Woodford, M. (1994): "Monetary Policy and Price Level Determinacy in a Cash-in-Advance Economy," Economic Theory, 4, 345-389.

(1995): "Price Level Determinacy without Control of a Monetary Aggregate," CarnegieRochester Series of Public Policy, 43, 1-46.

(2001): "Fiscal Requirements of Price Stability," Journal of Money, Credit, and Banking, $33,669-728$. 


\section{A The linearized model}

Once the model is solved, the variables can be rescaled in order to induce stationarity. The model is then linearized with respect to taxes, government expenditure, and debt, whereas it is loglinearized with respect to all the other variables. We obtain a system of equations:

1. IS curve:

$$
\begin{aligned}
\widehat{y}_{t}= & \widetilde{g}_{t}-\frac{1}{1+\Phi \gamma^{-1}} E_{t}\left(\widetilde{g}_{t+1}\right)+\frac{\Phi \gamma^{-1}}{1+\Phi \gamma^{-1}}\left(\widehat{y}_{t-1}-\widetilde{g}_{t-1}-a_{t}\right) \\
& -\frac{1-\Phi \gamma^{-1}}{1+\Phi \gamma^{-1}}\left[\widetilde{R}_{t}-E_{t}\left[\widetilde{\pi}_{t+1}\right]-\left(1-\rho_{d}\right) d_{t}\right]+\frac{1}{1+\Phi \gamma^{-1}}\left[E_{t}\left[\widehat{y}_{t+1}\right]+\rho_{a} a_{t}\right]
\end{aligned}
$$

2. Phillips curve:

$$
\begin{aligned}
\tilde{\pi}_{t}= & \frac{\kappa\left(1-\Phi \gamma^{-1}\right)^{-1}}{1+\varsigma \beta}\left(\left[1+\frac{\alpha}{1-\alpha}\left(1-\Phi \gamma^{-1}\right)\right] \widehat{y}_{t}-\widetilde{g}_{t}-\Phi \gamma^{-1}\left(\widehat{y}_{t-1}-\widetilde{g}_{t-1}-a_{t}\right)\right) \\
& +\frac{\varsigma}{1+\varsigma \beta} \widetilde{\pi}_{t-1}+\frac{\beta}{1+\varsigma \beta} E_{t}\left[\widetilde{\pi}_{t+1}\right]+\widetilde{\mu}_{t}
\end{aligned}
$$

where $\kappa \equiv \frac{1-v}{v \varphi \Pi^{2}}$.

3. Monetary policy rule (see below for other options):

$$
\widetilde{R}_{t}=\rho_{R, \xi_{t}^{s p}} \widetilde{R}_{t-1}+\left(1-\rho_{R, \xi_{t}^{s p}}\right)\left[\psi_{\pi, \xi_{t}^{s p}} \widetilde{\pi}_{t}+\psi_{y, \xi_{t}^{s p}}\left(\widehat{y}_{t}-\widehat{y}_{t}^{n}\right)\right]+\sigma_{R, \xi_{t}^{v o}} \epsilon_{R, t}
$$

4. Ratio between government purchases and total government expenditure:

$$
\widetilde{\chi}_{t}=\rho_{\chi} \widetilde{\chi}_{t-1}+\left(1-\rho_{\chi}\right) \iota_{y}\left(\widehat{y}_{t}-\widehat{y}_{t}^{n}\right)+\sigma_{\chi, \xi_{t}^{v o}} \epsilon_{\chi, t}
$$

5. Fiscal rule:

$$
\widetilde{\tau}_{t}=\rho_{\tau, \xi_{t}^{s p}} \widetilde{\tau}_{t-1}+\left(1-\rho_{\tau, \xi_{t}^{s p}}\right)\left[\delta_{b, \xi_{t}^{s p}} \widetilde{b}_{t-1}^{m}+\delta_{e}\left(\widetilde{e}_{t}^{S}+\widetilde{e}_{t}^{L}\right)+\delta_{y}\left(\widehat{y}_{t}-\widehat{y}_{t}^{*}\right)\right]+\sigma_{\tau, \xi_{t}^{v o}} \epsilon_{\tau, t}
$$

6. Debt:

$$
\widetilde{b}_{t}^{m}=\beta^{-1} \widetilde{b}_{t-1}^{m}+b^{m} \beta^{-1}\left(\widehat{R}_{t-1, t}^{m}-\widehat{y}_{t}+\widehat{y}_{t-1}-a_{t}-\widetilde{\pi}_{t}\right)-\widetilde{\tau}_{t}+\widetilde{e}_{t}^{S}+\widetilde{e}_{t}^{L}+\widetilde{t p}_{t}
$$

7. Return long term bond:

$$
\widehat{R}_{t, t+1}^{m}=R^{-1} \rho \widehat{P}_{t+1}^{m}-\widehat{P}_{t}^{m}
$$

8. No arbitrage:

$$
R_{t}=E_{t}\left[R_{t, t+1}^{m}\right]
$$


9. Federal expenditure, short term component:

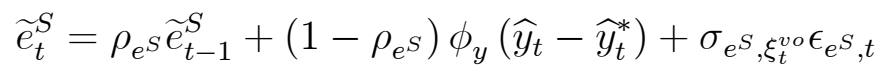

10. Federal expenditure, long term component:

$$
\widetilde{e}_{t}^{L}=\rho_{e^{L}} \widetilde{e}_{t-1}^{L}+\sigma_{e^{L}, \xi_{t}^{v o}} \epsilon_{e^{L}, t}
$$

11. Term premium:

$$
\widetilde{t p}_{t}=\rho_{t p} \tilde{t p}_{t-1}+\sigma_{t p, \xi_{t}^{v o}} \epsilon_{t p, t}
$$

12. Technology:

$$
a_{t}=\rho_{a} a_{t-1}+\sigma_{a, \xi_{t}^{v o}} \epsilon_{a, t}
$$

13. Demand shock:

$$
d_{t}=\rho_{d} d_{t-1}+\sigma_{d, \xi_{t}^{v o}} \epsilon_{d, t}
$$

14. Potential output:

$$
\left[\frac{1}{1-\Phi \gamma^{-1}}+\frac{\alpha}{1-\alpha}\right] \widehat{y}_{t}^{*}=\frac{1}{1-\Phi \gamma^{-1}} \widetilde{g}_{t}+\frac{\Phi \gamma^{-1}}{1-\Phi \gamma^{-1}}\left(\widehat{y}_{t-1}^{*}-\widetilde{g}_{t-1}-a_{t}\right)
$$

15. Definition of $\chi_{t}$ :

$$
\widetilde{\chi}_{t}=\frac{1}{g-1} \widetilde{g}_{t}-e^{-1} \widetilde{e}_{t}
$$

16. Mark-up shock:

$$
\widetilde{\mu}_{t}=\rho_{\widetilde{\mu}} \widetilde{\mu}_{t-1}+\sigma_{\widetilde{\mu}, \xi_{t}^{v o}} \epsilon_{\widetilde{\mu}, t}
$$

where $\widetilde{\mu}_{t}=\frac{\kappa}{1+\varsigma \beta} \log \left(\aleph_{t} / \aleph\right)$ is the percentage deviation of the rescaled markup from its own steady state, with $\aleph_{t}=\frac{1 / v_{t}}{1 / v_{t}-1}$.

\section{B MCMC algorithm and convergence}

Draws from the posterior are obtained using a standard Metropolis-Hastings algorithm initialized around the posterior mode. When working with models whose posterior distribution is very complicated in shape it is very important to find the posterior mode. In a MS-DSGE model, this search can turn out to be an extremely time-consuming task, but it is a necessary step to reduce the risk of the algorithm getting stuck in a local peak. Here are the key steps of the Metropolis-Hastings algorithm:

- Step 1: Draw a new set of parameters from the proposal distribution: $\vartheta \sim N\left(\theta_{n-1}, c \bar{\Sigma}\right)$ 
- Step 2: Compute $\alpha\left(\theta^{m} ; \vartheta\right)=\min \left\{p(\vartheta) / p\left(\theta^{m-1}\right), 1\right\}$ where $p(\theta)$ is the posterior evaluated at $\theta$.

- Step 3: Accept the new parameter and set $\theta^{m}=\vartheta$ if $u<\alpha\left(\theta^{m} ; \vartheta\right)$ where $u \sim U([0,1])$, otherwise set $\theta^{m}=\theta^{m-1}$

- Step 4: If $m \leq n^{\text {sim }}$, stop. Otherwise, go back to step 1

The matrix $\bar{\Sigma}$ corresponds to the inverse of the Hessian computed at the posterior mode $\bar{\theta}$. The parameter $c$ is set to obtain an acceptance rate of around 35\%. The posterior is obtained combining the priors with the likelihood computed using the modified Kalman filter described in Kim and Nelson (1999).

Table 3 reports results based on the Brooks-Gelman-Rubin potential reduction scale factor using within and between variances based on the five multiple chains used in the paper. The eight chains consist of 540,000 draws each (1 every 200 draws is saved). The numbers are well below the 1.1 benchmark value used as an upper bound for convergence.

\section{Dataset}

Real GDP, the GDP deflator, and the series for fiscal variables are obtained from the Bureau of Economic Analysis. We follow Leeper, Plante, and Traum (2010) in constructing the fiscal variables. The fiscal series are built using NIPA Table 3.2. (Federal Government Current Receipts and Expenditures). Government purchases (G) are computed as the sum of consumption expenditure (L21), gross government expenditure (L42), net purchases of non-produced assets (L44), minus consumption of fixed capital (L45), minus wage accruals less disbursements (L33). Total government expenditure is obtained summing government purchases with transfers. Transfers are given by the sum of net current transfer payments (L33-L16), subsidies (L32), and net capital transfers (L43-L39). Tax revenues are given by the difference between current receipts (L38) and current transfer receipts (L16). All variables are then expressed as a fraction of GDP. Government purchases are transformed in a way to obtain the variable $g_{t}$ defined in the model. The series for the FFR is obtained averaging monthly figures downloaded from the St. Louis Fed web-site. Finally, we depart from other papers in the literature that reconstruct the series for government debt using the interest payments reported in the NIPA tables and instead we use the debt series at market values from the Dallas Fed web-site. Hall and Sargent (2011) argue that the interest payments reported by the Government are not consistent with any well defined law of motion for debt. Specifically, the Government reports data that do not fully take into account revaluation effects. Revaluation effects are important in the context of our model that allows for a maturity structure of government debt. However, as explained by Leeper, Plante, and Traum (2010), the two series are highly correlated implying that the choice of the series for debt is going to play only a minor role in the context of a structural estimation. 
Potential Scale Reduction Factor

\begin{tabular}{cc|cc|cc|cc}
\hline \hline Parameter & PSRF & Parameter & PSRF & Parameter & PSRF & Parameter & PSRF \\
\hline$\psi_{\pi, P M}$ & 1.03 & $H_{11}^{s p}$ & 1.01 & $\sigma_{R, 1}$ & 1.01 & $\sigma_{R, 2}$ & 1.00 \\
$\psi_{y, P M}$ & 1.02 & $H_{22}^{s p}$ & 1.03 & $\sigma_{\chi, 1}$ & 1.00 & $\sigma_{\chi, 2}$ & 1.00 \\
$\rho_{R, P M}$ & 1.01 & $H_{33}^{s p}$ & 1.02 & $\sigma_{a, 1}$ & 1.00 & $\sigma_{a, 2}$ & 1.00 \\
$\rho_{\tau, A F}$ & 1.00 & $H_{12}^{s p}$ & 1.09 & $\sigma_{\tau, 1}$ & 1.00 & $\sigma_{\tau, 2}$ & 1.00 \\
$\psi_{\pi, A M}$ & 1.01 & $\varsigma$ & 1.00 & $\sigma_{d, 1}$ & 1.00 & $\sigma_{d, 2}$ & 1.00 \\
$\psi_{y, A M}$ & 1.04 & $\rho_{\chi}$ & 1.00 & $\sigma_{e^{S}, 1}$ & 1.01 & $\sigma_{e^{S}, 2}$ & 1.00 \\
$\rho_{R, A M}$ & 1.01 & $\rho_{a}$ & 1.00 & $\sigma_{t p, 1}$ & 1.00 & $\sigma_{t p, 2}$ & 1.00 \\
$\rho_{\tau, P F}$ & 1.00 & $\rho_{e}$ & 1.02 & $\sigma_{\mu, 1}$ & 1.00 & $\sigma_{\mu, 2}$ & 1.00 \\
$\delta_{b, P F}$ & 1.00 & $\rho_{d}$ & 1.06 & $\pi$ & 1.01 & $H_{11}^{v o}$ & 1.00 \\
$\delta_{e}$ & 1.00 & $\rho_{\mu}$ & 1.00 & $\gamma$ & 1.00 & $H_{22}^{v o}$ & 1.00 \\
$\delta_{y}$ & 1.01 & $\iota_{y}$ & 1.02 & $b$ & 1.00 & & \\
$\Phi$ & 1.03 & $\phi_{y}$ & 1.01 & $g$ & 1.00 & & \\
$\kappa$ & 1.01 & $\rho_{t p}$ & 1.00 & $\tau$ & 1.00 & & \\
\hline \hline
\end{tabular}

Table 3: The table reports the Gelman-Rubin Potential Scale Reduction Factor (PSRF) for eight chains of 540,000 draws each (1 every 200 is stored). Values below 1.1 are regarded as indicative of convergence.

\section{Additional Results (not for publication)}

This appendix reports some additional figures and results. Figure 14 reports the median and $90 \%$ bands for the smoothed probabilities of the different regimes based on the 1,350,000 parameter draws retained for the estimates. Figure 15 shows that the results derived in Subsection 4.1 hold even when agents are assumed to be aware of the possibility of regime changes when under the AM/PF. Figure 16 reports the variance decomposition across different policy regimes assuming that the economy is currently under the high volatility regime.
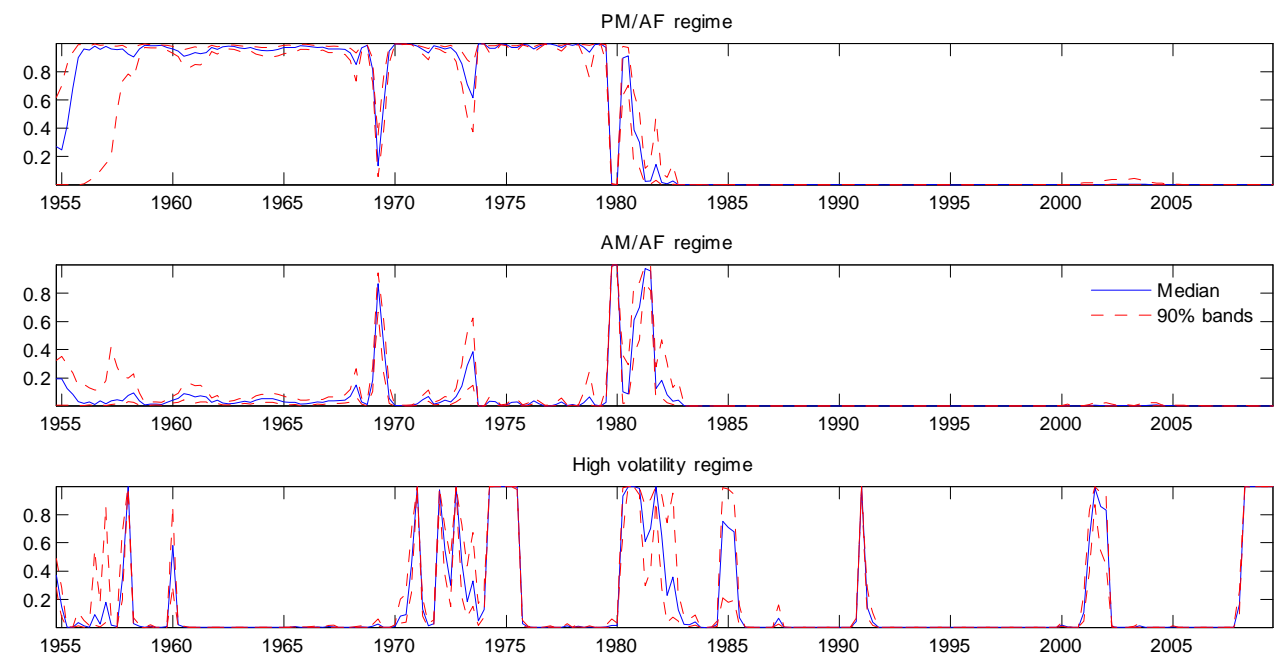

Figure 14: The figure reports the median and $90 \%$ bands for the smoothed probabilities of the different regimes based on the 1,350,000 parameter draws retained for the estimates. 

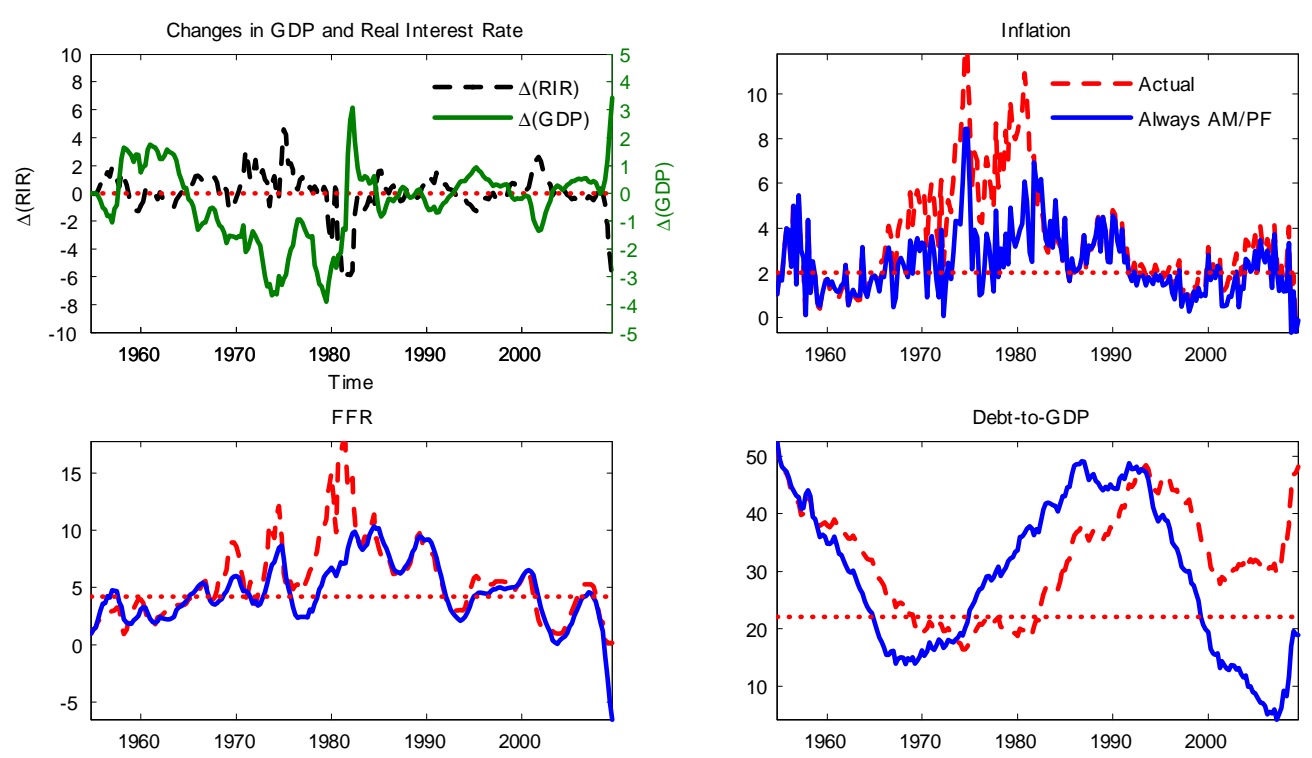

Figure 15: The Great Inflation: Always AM/PF. Counterfactual simulation in which non-policy shocks are left unchanged and the benchmark $\mathrm{AM} / \mathrm{PF}$ regime is assumed to be in place over the entire sample. Notice that under the benchmark $\mathrm{AM} / \mathrm{PF}$ regime agents do not regard the AM/PF regime as the only possible one.
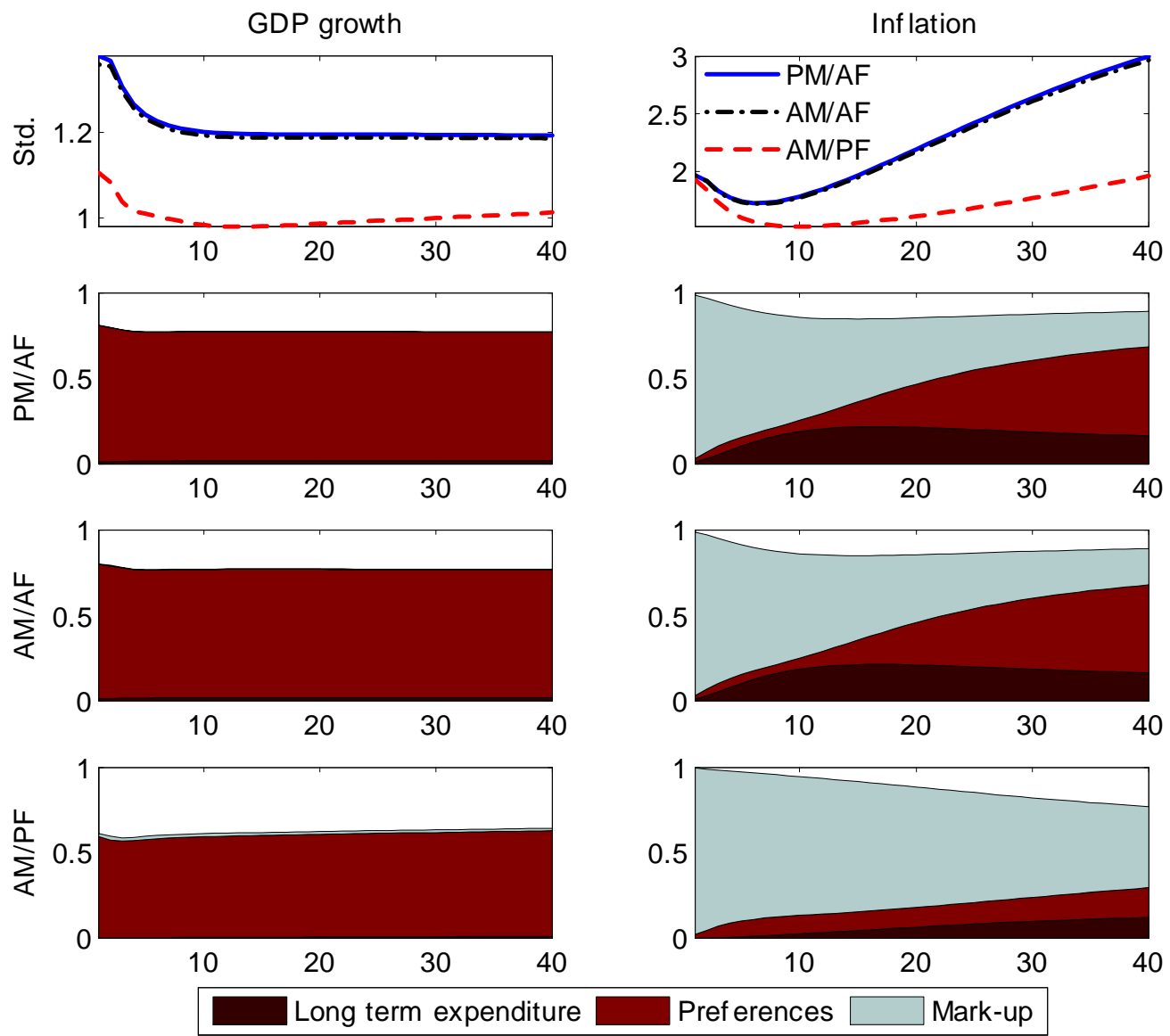

Figure 16: The first row reports the model implied standard deviations at different horizons for output growth and inflation across different initial policy combinations. The high volatility regime is assumed to be in place at time zero. Both the standard deviations and variance decompositions take into account the possibility of regime changes. 